\title{
Modelling of steel frames using advanced beam and joint elements with interfaces governed by beam modes
}

Hansen, Anders Bau; Jönsson, Jeppe

Published in:

Thin-Walled Structures

Link to article, DOI:

10.1016/j.tws.2019.106430

Publication date:

2019

Document Version

Peer reviewed version

Link back to DTU Orbit

Citation (APA):

Hansen, A. B., \& Jönsson, J. (2019). Modelling of steel frames using advanced beam and joint elements with interfaces governed by beam modes. Thin-Walled Structures, 145, [106430].

https://doi.org/10.1016/j.tws.2019.106430

\section{General rights}

Copyright and moral rights for the publications made accessible in the public portal are retained by the authors and/or other copyright owners and it is a condition of accessing publications that users recognise and abide by the legal requirements associated with these rights.

- Users may download and print one copy of any publication from the public portal for the purpose of private study or research

- You may not further distribute the material or use it for any profit-making activity or commercial gain

- You may freely distribute the URL identifying the publication in the public portal

If you believe that this document breaches copyright please contact us providing details, and we will remove access to the work immediately and investigate your claim 


\title{
Modelling of steel frames using advanced beam and joint elements with interfaces governed by beam modes
}

\author{
Anders Bau Hansen ${ }^{\mathrm{a}, \mathrm{b}}$, Jeppe Jönsson ${ }^{\mathrm{a}, *}$ \\ ${ }^{a}$ Technical University of Denmark, Department of Civil Engineering, Brovej Building 118, DK-2800 Kgs. Lyngby, Denmark \\ ${ }^{b}$ NIRAS A/S, Sortemosevej 19, DK-3450 Allerød, Denmark
}

\begin{abstract}
For decades, engineers have assessed and analysed steel frames using simple joints between beams and columns. These joints are often based on oversimplified assumptions using hinges or a direct transfer of beam displacements without any relative displacements. More seldom is the use of spring models that allow relative beam and column displacements at the joints. This despite the standardised component method approach, which can be used to determine the rotational spring stiffness of the relative rotation in a joint. This paper gives a background overview of essential developments in joint modelling and generalised thin-walled beam modelling, including torsional, distortional and related warping effects. For particular situations, some recent proposals for joint models can be applied to joints between thin-walled beams. On this basis, this paper presents a novel idea and a generic methodology that allows the interface between an extended number of generalised beam displacement modes and joints that are modelled using shell elements. The main novelty is the idea to transform from standard degrees of freedom of the interface into a reduced number of beam displacement mode related degrees of freedom. Thus, the number of degrees of freedom of the joint can be reduced to the corresponding total sum of beam modes that have been chosen for the modelling of each of the connected beam elements. The total number of degrees of freedom used for modelling the complete framework will depend on the selected number of modes in each beam element and on the number of extra internal modes chosen in the joint models. For enhanced structural analysis with advanced beam elements and joints that allow relevant distortions and built-in refined connection components, it is believed that this methodology will enable the full detailed analysis of large steel frameworks with a reasonable number of degrees of freedom.
\end{abstract}

Keywords: Steel frames, beam theories, joint analysis, mode-based formulation

\section{Introduction}

Steel frameworks have been used for decades in a broad range of engineering fields; maritime, aerospace, offshore, civil and mechanical engineering. In the construction industry, steel is commonly used in larger frame and truss structures such as sports arenas, power plants, cranes, high rise buildings and bridges. This paper focus on the analysis of steel frameworks using advanced generalised thin-walled beams with an expanded number of displacement modes and the interface to shell joint models. Thus, achieving a more detailed assessment of the steel framework with a much-improved beam and joint modelling. In fact, this paper presents the general idea of a novel generic methodology to model joints interfacing between beams and columns. The proposed methodology extends the usability of mode-based beam elements to model frames.

The daily practice in the design of structural steel frameworks is to use the simplified approach of assuming the

\footnotetext{
* Corresponding author

Email address: jej@byg.dtu.dk (Jeppe Jönsson)
}

joints to be either ideally pinned or fully rigid. This practice happens despite that design codes, such as Eurocode 3 [1], allows engineers to consider a semi-rigid behaviour of steel joints through the 'Component Method' and also despite that studies have indicated savings in the range of $7 \%-26 \%$ considering semi-rigid behaviours $2,3,4$, 4 . The simplified approach is often chosen to keep the analysis as simple as possible even though connections seldom fulfil such behaviours [5]. Usually a joint should be categorised as semi-rigid, reflecting a behaviour where relative rotations occur when transmitting bending moments between adjacent members. Furthermore, considering such a simplified approach, valuable knowledge regarding joint behaviour is lost. Especially in thin-walled structures in which effects such as warping becomes an essential issue [6].

Consequently, the structural designer is left with the choice to perform quite costly experimental investigations or numerical investigations by consulting sophisticated finite element computer software, which requires a timeconsuming process of data input and result interpretation. Furthermore, such finite element assessment is prohibited for routine applications in frame analysis. Thus, 
dedicated methods for frame analysis with enhanced thinwalled beam modelling and enhanced joint modelling are in demand. It has been shown in [7 that advanced analysis of thin-walled beam members can be achieved with a reduced number of degrees of freedom by considering a displacement-based mode formulation where judiciously chosen deformation modes are selected and thereby only $25 \%$ of the degrees of freedom are needed compared to commercial finite element software using shell elements. However, by using only one advanced thin-walled beam element between joints in linear analysis, this reduction is believed to be even higher depending on the number of beam modes taken into account.

The following subsections give a background overview of some of the crucial developments in joint modelling and generalised thin-walled beam modelling.

\subsection{Semi-rigid connections}

The very first reported investigations on the rigidity of joints in steel structures was assessed by Wilson \& Moore in 1917 [8] regarding experiments on riveted connections. Later, around the mid-1930s, a more general elaboration on the rigidity of joints was given considering the relationship between the moment and rotation occurring at the joint as well as the overall influence on the global structure, see e.g. [9]. Modifications have been implemented in theories, such as rotational springs between beam-ends to reflect the joint stiffness [10]. In such cases, the joint is represented by a finite stiffness, and improved structural response is achieved. However, the task of establishing an adequate spring stiffness is difficult. In a review given by Diaz et al. 11] referring 180 papers a broad range of models and procedures are given on how to implement and take advantage of the semi-rigid joint design. It is concluded that the most accurate prediction is through experiments yielding a true non-linear behaviour between moment and rotation as shown in Figure 1, which illustrates the idealised moment-rotation curves of different joint configurations. Furthermore, Diaz et al. states that one of the most used methods is the mechanical model also adopted in the Eurocode 3 [1, 12] namely the 'Component Method'.

The Component Method is an idealisation of a joint into a mechanical model including linear springs and rigid links. As an example of mechanical modelling see the simple beam-to-column connection in Figure 2. This connection is exposed to a bending moment $M$ that will cause a relative rotation $\phi$ that will induce tension, compression and shear within the connection. Hence, the Component Method represents these effects through mechanical components. For this purpose, the joint is divided into components each represented by a spring stiffness. In the simplified case illustrated in Figure 2 these are: $k_{1}$ column web panel in shear, $k_{2}$ column web in transverse compression, and $k_{3}$ column web in transverse tension. The linear spring stiffness/behaviour of each component is derived depending on the geometrical joint configurations. This derivation is to a great extent based on empirical equations, e.g. 13. The method is, however, limited to asses joints exposed to bending moments and not able to take shear and normal forces into account [1. Recently, modifications have been presented by Bayo et al. [14, 15]. They use a 'joint element' to which beams and columns are attached. The stiffness of this joint element is then found using the same component stiffness's as in the Component Method, but with this method, eccentricities are incorporated right away while several iterations are avoided compared to the classic Component Method. Another variation in the Component Method is given by Silva et al. [16] presenting a bi-linear spring model to achieve more accurate results covering the plastification of the joint. A special spring model is developed and gives an idealised bi-linear behaviour of each component. Hence, each component may be represented by a linear elastic part followed by a linear plastic strain hardening zone (see Figure $22_{2}$ ). A 'Generalized Component Method' was presented by Zhu et al. 17 adopting Silva's approach. Zhu and co-workers consider a tri-linear model to include both elastic, plastic and post yielding behaviours. See Figure $2{ }_{3}$.

\subsection{Torsional effects in thin-walled beams}

In the second half of the twentieth century, the interest in using thin-walled steel components increased heavily. This increase was highly due to its excellent stiffness-toweight ratio and its strength-to-width ratio with the main purpose of lightening engineering structures by saving materials. Some of the pronounced pioneers with respect to thin-walled structures were Timoshenko [18, 19, [20, Flügge \& Marguerre [21], Vlasov [22], and Kollbrunner \& Hajdin [23]. They realised that non-negligible normal stresses were developed leading to warping deformations not included in the beam theories at that time. Therefore a demand for new theories was born. Accordingly, theories, such as Vlasov's 'Thin-Walled Elastic Beams', were implemented considering an extra seventh degree of freedom representing the warping effect based on torsion and the sectorial coordinate also introduced by Vlasov.

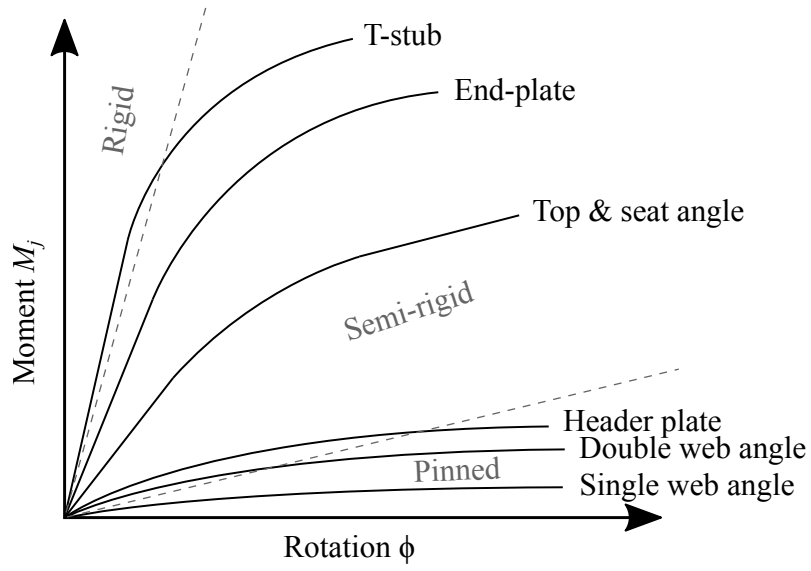

Figure 1: Idealised moment-rotation curves 


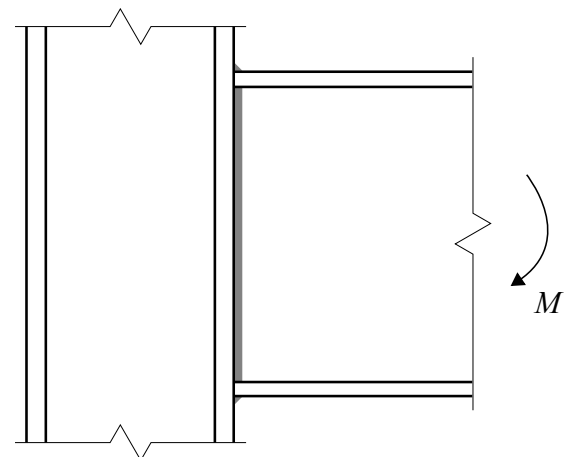

a)

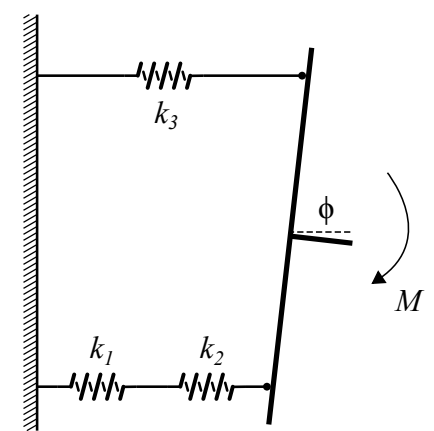

b)

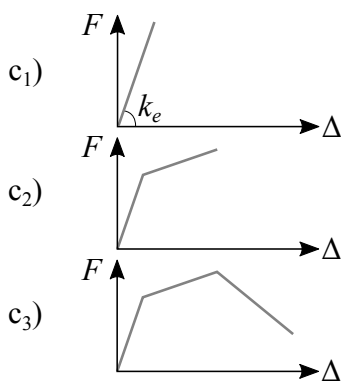

c)

Figure 2: The Component Method: a) A welded beam-to-column connection consisting of two I-beams exposed to a bending moment $M, \mathrm{~b})$ idealisation of the connection $\left(k_{1}, k_{2}, k_{3}\right.$ being spring stiffness's and $\phi$ the relative rotation), and c) spring behaviours of different approaches; $c_{1}$ ) the classic Component Method [1], $c_{2}$ ) proposed by Silva et al. [16] having a bi-linear behaviour, and $c_{3}$ ) used by Zhu et al. [17] with a tri-linear behaviour

Examples on approaches adopting the seventh degree of freedom are Krajcinovic 24 and Barsoum \& Gallagher 25] who investigated stability and dynamics, and torsion and lateral stability of thin-walled beams, respectively. They introduced finite beam elements with the seventh degree of freedom reflecting Vlasov's theory. With the proposed finite beam elements it is possible to analyse frames more accurately by taking warping into account. However, depending on the joint configuration, the amount of warping being transmitted is restrained and a Vlasov beam element yield erroneous results due to inadequate warping restraint and transmission. Thus, with the recognition of warping's presence, the transmission of local warping, as well as rotation and warping from torsion occurring at beam-ends, became the main task to include when connecting non-aligned beams, for example at frame corners. However, a proposal to avoid this was given by Baigent \& Hancock [26] connecting non-aligned open channel profiles with flat plates. More regular joint configurations were assessed by Vacharajittiphan \& Trahair [27] investigating the warping restraint stiffness in non-aligned doubly symmetric I-sections in four different joint configurations being: unstiffened, partially stiffened with a single diagonal stiffener, box stiffened, and fully stiffened with three stiffening plates, see Figure $3 \mathrm{a}_{1}$ to $3 \mathrm{~d}_{1}$. Similar investigations on warping transmission through joints were carried out by Morrell et al. 28] considering the relationship between end section torsional rotations in orthogonal plain open channel section members, or Sharman 29 and Krenk \& Damkilde [30] who dealt with warping transmission of arbitrarily oriented members both assessing I-sections and open channel sections. Different joint configurations were assessed where the member webs were laying in the same plane. Lastly, Masarira [31] deduced coefficients approximating the joint effect on lateral torsional buckling load of steel frames based on a shell finite element analysis concluding that the warping effect profoundly influences the stability.

To this end, it seems that warping torsion is a significant effect and should be incorporated in the analysis of the structural response assessing open thin-walled members. However, methods taking this into account in frame analysis often fail. Yang \& McGuire proposed a 'warping indicator' adjusting the restriction of warping at each beam-end 32 (a warping spring to characterise warping). Another approach was given by Tong et al. 33] presenting a warping transmission model for beam-to-column rigid joints with diagonal stiffeners. A third approach to be mentioned modelling joints in thin-walled frames have been given by Shayan \& Rasmussen 34 introducing a 'joint element' in a beam finite element environment. Here, beam-ends are connected by the use of springs and linear constraint equations, which are derived beforehand based on a shell finite element discretisation and assessment of the joint element. Nevertheless, the mentioned approaches are all limited to seven degrees of freedom not considering detailed crosssection investigations able to include distortional effects.

\subsection{Distortional effects in thin-walled beams}

The cross-sections of thin-walled beams do not keep their shape during deformation - they distort. A small infinitesimal cut-out of a wall element has to be in equilibrium and to establish this equilibrium the cross-section deforms. Furthermore, instability effects will also induce local and distortional buckling. Thus, beams and columns with thin-walled cross-sections are prone to non-rigid inplane deformations.

A well-known beam theory that handles this effect is the one Schardt introduced in 1966. Namely, the 'Generalised Beam Theory', (GBT). He introduced it in Germany as 'Verallgemeinerte Technische Biegetheorie' (VTB) assessing open thin-walled cross-sections, [35, 36. Later, he modified it to include closed cross-sections as well. The theory is essentially based on a folded plate theory and the idea of expanding the displacements as a sum of displacement modes. To explain, this theory is a mode-based beam theory relying on orthogonal cross-section displacement fields with associated axial variations. All modes 


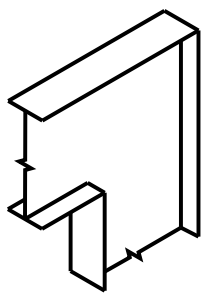

$\left.a_{1}\right)$

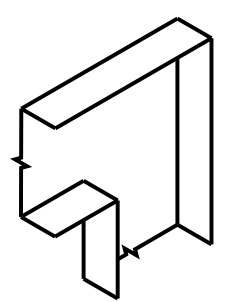

$\left.\mathrm{a}_{2}\right)$

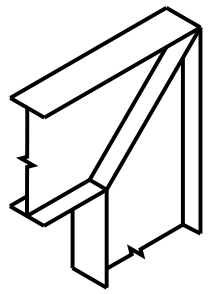

$\left.\mathrm{b}_{1}\right)$

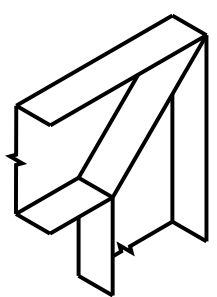

$\left.b_{2}\right)$

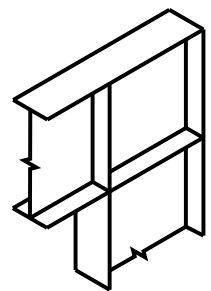

$\left.\mathrm{c}_{1}\right)$

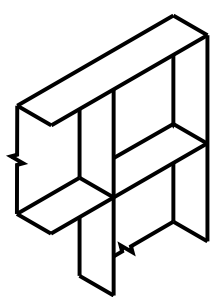

$\left.c_{2}\right)$

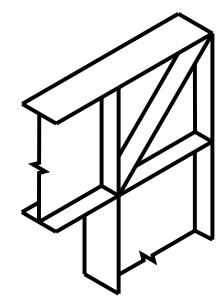

$\left.\mathrm{d}_{1}\right)$

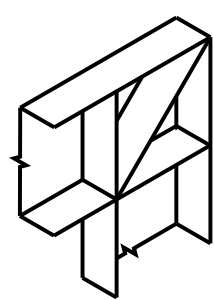

$\left.d_{2}\right)$

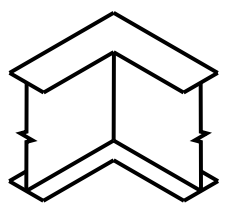

$\left.\mathrm{e}_{1}\right)$

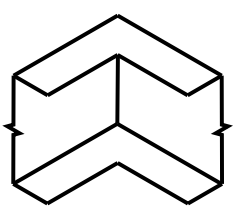

$\left.\mathrm{e}_{2}\right)$

Figure 3: Frame corners with different stiffness configurations connecting two in-plane I-beams or two open channel sections, respectively. a) to d) having web continuity and a) unstiffened, b) diagonal stiffened, c) box stiffened, d) box and diagonal stiffened, whereas e) unstiffened with flange continuity

are linearly combined with varying intensities yielding the final deformation response. That is, a deformation is decomposed into a number of known displacement modes. Another proposal to a thin-walled beam theory taking distortion into account was given by Kollbrunner \& Hajdin. They extended their thin-walled theory to include distortional in-plane deformations as well, even considering both open and closed cross-sections [37]. British investigators on cold-formed steel members adopted the Generalised Beam Theory and published several papers, 38, 39, leading to an internationalisation of the theory and whereby it became known by the acronym 'GBT'. Subsequently, GBT was extended to handle orthotropic materials such as fibre reinforced polymers (FRP) by Silvestre and Camotim 40, 41. In the latest decades inclusion of non-linearities [42, plasticity [7, and a more general shear strain formulation [43, 44 have been incorporated, besides the already implemented first-order, buckling and post-buckling analysis as well as dynamic assessments. See also [45, 46].

Simultaneously with the development of GBT, the 'Finite Strip Method' (FSM) has been further developed. Based on the work of Wittrick [47] and Przemieniecki [48], Cheung 49 formulated the FSM as we know it today. The essentials of this theory are: the discretisation of the beam element into narrow strips running the entire beam length being rigidly joint together, the cross-sectional deformations being interpolated by polynomial functions assuming a Kirchhoff plate bending behaviour, and the axial variation found as sinusoidal functions. Among others, Hancock used this theory to deduce buckling curves or so-called signature curves for thin-walled members, 50. However, the main lack in this theory is the missing decomposition of deformations into known displacement modes. Accordingly, Ádány \& Schafer introduced this to the FSM, [51, [52] leading to the theory named 'constrained FSM' (cFSM) enabling mode decomposition and identification, [53, 54]. Silvestre et al. [55] compare the derivations of the crosssectional displacement fields in the GBT and FSM being on same mechanical properties. Furthermore, Ádány et al. 56] compares the results obtained using the two approaches concluding nearly similar results. However, GBT and cFSM differ in the determination of the axial variation functions. Where, GBT formulates finite beam elements with a variation between end cross-sections as interpolations by use of Hermite cubic standard finite beam element functions, the cFSM uses a geometrical approach having sinusoidal amplitude functions.

As a matter of fact, the displacement mode decomposition has been seen as an efficient tool by many. Hence, others who adopted the idea of separating the beam deformation responses into orthogonal displacement modes were, for example Jönsson [57] who deduces the extra warping and distortional mode for thin-walled beams, or Jönsson \& Andreassen [58, 59, 60], and Vieira et al. [61, 62] who determined cross-sectional displacement fields based on a generalised eigenvalue problem. This also reveals the axial amplitude functions as polynomial and exponential functions without limiting the beam element to have a finite length, which for example is the case in GBT. Garcea et al. 63. deduce cross-sectional displacement fields as generalised eigenvectors (GE) as well. The obtained results are compared with the GBT nearly being coincidental.

A new development is also the 'constrained finite element method' (cFEM) by Ádány 64, 65, 66, 67, in which a special purpose finite element is formulated and constrained to adhere to certain displacement mode constraints. A common point of the theories mentioned above is the inclusion of cross-sectional distortion effects. Often the displacement modes are also ordered in local, distortional and global modes. 
Although very detailed beam theories have been developed, it is difficult to use these for analysis of frame structures. The main reason is the lack of methods that satisfyingly allow an interface between connected members at a joint. The most successful proposals have been implemented in the framework of GBT by Basaglia et al. [68, 69, 70, 71, 72, 73, 74, 75]. The primary focus has been on joint configurations as illustrated in Figure 3 With their approach, they introduced a 'joint element' between non-aligned finite GBT beam elements. However, difficulties have been met due to the modal nature of GBT (being a GBT-method with non-standard nodal degrees of freedom for cross-sectional displacements), which was not able to be transferred to the joint element formulation. In their formulation, the joint element is represented by the seven generalised displacements known from the Vlasov theory allowing a warping transmission from non-uniform torsion. Additionally, a number of constraint equations have been added to fulfil displacement continuity between adjacent members (i.e. to include local and distortional effects). The constraint equations highly depend on the joint geometry. This method requires prior knowledge of the joint to establish the correct constraint prerequisites before performing a proper frame analysis.

\section{Proposal of a new methodology}

Although Basaglia and co-workers have presented procedures for assessing frames of thin-walled members including torsional and distortional effects, the methods are limited to specific types of cross-sections and joints. It is believed that a more generic and general methodology needs to be developed so that joints between advanced thin-walled beams can be established and modelled by use of more conventional finite element modelling, which can be performed by engineering offices.

\subsection{The idea}

In general, the idea is to model beam and column members using an advanced beam element formulation that is based on displacement modes, which includes warping and distortional deformations. On the other hand, the connections between advanced beam elements shall be modelled by use of more traditional finite elements, e.g. finite shell elements. Both the advanced beam elements and the joint elements are modelled such that all nodes within a discretised interface have six degrees of freedom each.

The mode-based formulation is performed by letting an advanced beam element be expressed by beam displacement modes instead of traditional nodal degrees of freedom. Each beam displacement mode is formulated as a combination of cross-sectional displacement fields, which contains transverse as well as warping displacements, and an amplitude function that describes the variation of the cross-sectional displacement field along the beam member. Hence, instead of standard finite element degrees of freedom at the interfaces between beam elements and joint elements the connected faces will be governed by the cross-sectional beam displacement fields that will be used as novel modal degrees of freedom. Accordingly, the connected faces at a joint element must likewise be transformed into this modal-based formulation, which is governed by the beam displacement modes. Furthermore and of utmost importance, with a modal formulation of the thin-walled beam elements, it is possible to reduce the number of modes to the most relevant, judiciously selected modes, and thereby reduce the number of modal degrees of freedom at the interfaces both regards to the beam member and the joint element. This reduction is done by transforming the conventional displacement degrees of freedom of the cross-section interface between a beam element and a joint element into the chosen modal displacements of the beam, and then use these modal displacements as the degrees of freedom at the interfaces. Hence, the nodal degrees of freedom at the connected faces are transformed into the chosen beam modal degrees of freedom. The unselected (irrelevant) modal degrees of freedom are assumed to be non-existing (zero). As a result, the frame behaviour is expressed in a displacement-based modal language yielding the opportunity of regulating the number of included modal degrees of freedom.

It is reasonable to assume that the same beam and joint configurations are represented several times within a frame structure. This may be utilised during the programming of the stiffness formulations and during back substitution of displacements, stresses and strains in members and joints.

To give the best possible grasp of the idea presented, a two-dimensional example will be referred to throughout the following subsections. For simplicity this illustrative example only includes in-plane degrees of freedom even though the presented idea is valid for a full threedimensional analysis. The example includes three advanced beam elements and a single joint element, which for example could represent a beam-to-column connection in a larger frame structure as illustrated in Figure 4

\subsection{Beam elements}

In-between connections, beam members and column members will be modelled using a beam element based on an advanced beam theory with torsional and distortional effects including the related cross-sectional warping deformations. To be able to describe the cross-sectional displacements, the cross-section is discretised into wall segments between nodes that have six displacement degrees of freedom each. Thus, the ends of a beam have several wall elements and several nodes, see also Figure 5. This results in an interface to which joints modelled using finite (shell) elements with conventional translational and rotational degrees of freedom at the nodes can be connected to. To derive the conventional linear elastic stiffness equation that governs the advanced beam element problem, a set of orthogonal cross-sectional displacement modes is used and 
!- Node with in-plane degrees of freedom

Beam degrees of freedom:

$$
\mathbf{u}^{\mathrm{B} 1}=\left[\begin{array}{l}
\mathbf{u}_{1}^{\mathrm{B} 1} \\
\mathbf{u}_{2}^{\mathrm{B} 1}
\end{array}\right] \quad \mathbf{u}^{\mathrm{B} 2}=\left[\begin{array}{c}
\mathbf{u}_{1}^{\mathrm{B} 2} \\
\mathbf{u}_{2}^{\mathrm{B} 2}
\end{array}\right] \quad \mathbf{u}^{\mathrm{B} 3}=\left[\begin{array}{c}
\mathbf{u}_{1}^{\mathrm{B}} \\
\mathbf{u}_{2}^{\mathrm{B} 3}
\end{array}\right]
$$

Joint degrees of freedom:

$$
\mathbf{u}^{\mathrm{J} 1}=\left[\begin{array}{l}
\mathbf{u}_{1}^{\mathrm{J} 1} \\
\mathbf{u}_{2}^{\mathrm{J} 1} \\
\mathbf{u}_{3}^{\mathrm{J} 1}
\end{array}\right]
$$

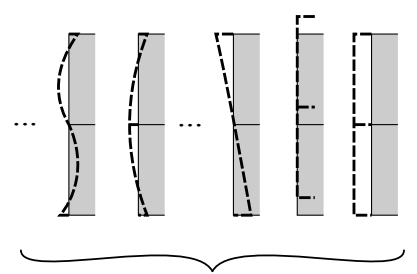

Cross-sectional displacemenet fields contained in $\mathbf{V}_{1}^{\mathrm{B} 1}$ and governed by the modal degrees of freedom in $\varphi^{\mathrm{B} 1}$
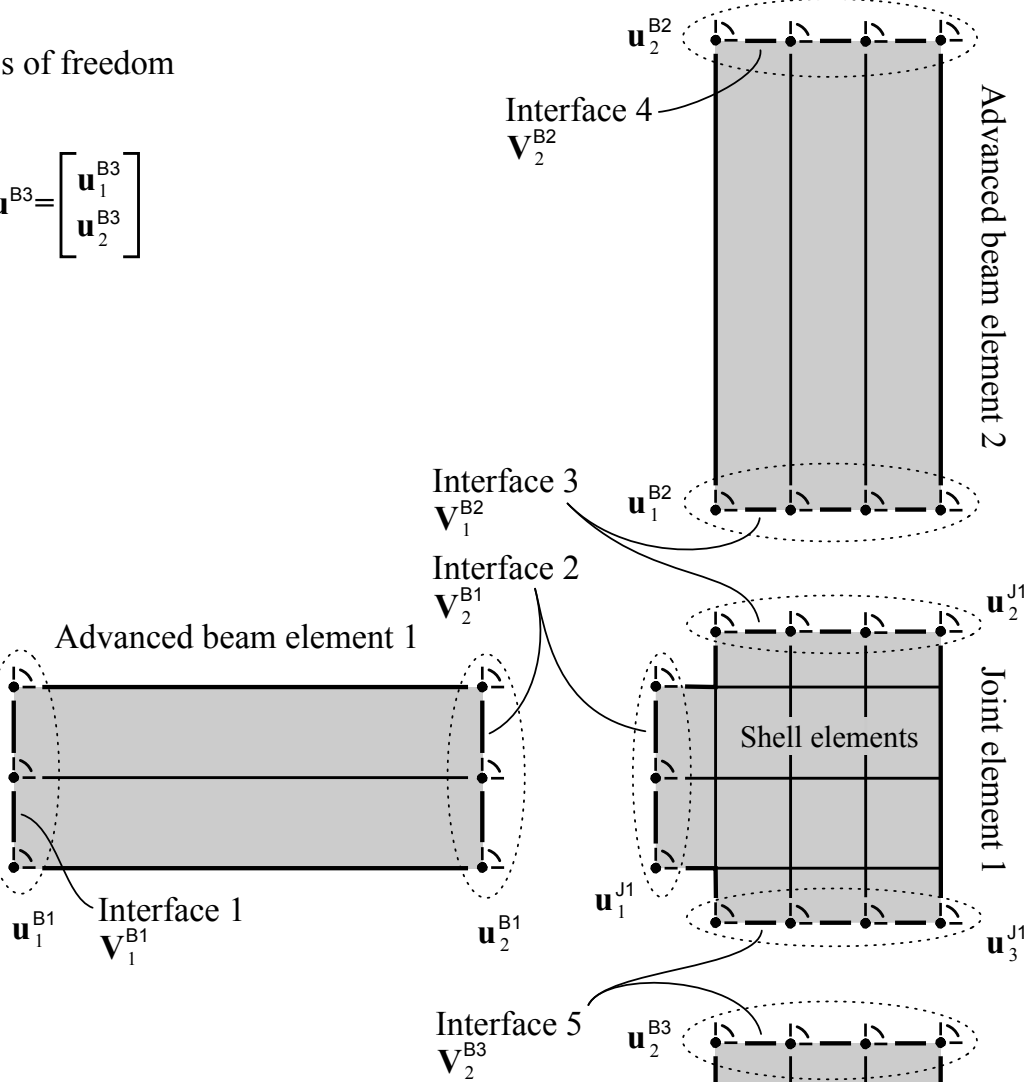

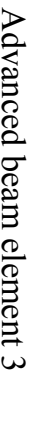

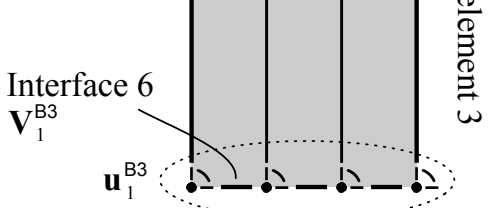

Beam transformation matrices:

$$
\mathbf{T}^{\mathrm{B} 1}=\left[\begin{array}{cc}
\mathbf{V}_{1}^{\mathrm{B} 1} & \cdot \\
\cdot & \mathbf{V}_{2}^{\mathrm{B} 1}
\end{array}\right] \quad \mathbf{T}^{\mathrm{B} 2}=\left[\begin{array}{cc}
\mathbf{V}_{1}^{\mathrm{B} 2} & \cdot \\
\cdot & \mathbf{V}_{2}^{\mathrm{B} 2}
\end{array}\right] \quad \mathbf{T}^{\mathrm{B} 3}=\left[\begin{array}{cc}
\mathbf{V}_{1}^{\mathrm{B} 3} & \cdot \\
\cdot & \mathbf{V}_{2}^{\mathrm{B} 3}
\end{array}\right]
$$

Joint transformation matrix:

$$
\mathbf{T}^{\mathrm{J} 1}=\left[\begin{array}{ccc}
\mathbf{V}_{2}^{\mathrm{B} 1} & \cdot & \cdot \\
\cdot & \mathbf{V}_{1}^{\mathrm{B} 2} & \cdot \\
\cdot & \cdot & \mathbf{V}_{2}^{\mathrm{B} 3}
\end{array}\right]
$$

Figure 4: A two-dimensional example for illustration purpose

hence:

$$
\mathbf{K}^{\mathrm{B}} \mathbf{u}^{\mathrm{B}}=\mathbf{f}^{\mathrm{B}} \quad \text { where } \mathbf{u}^{\mathrm{B}}=\left[\begin{array}{c}
\mathbf{u}_{1}^{\mathrm{B}} \\
\mathbf{u}_{2}^{\mathrm{B}}
\end{array}\right]
$$

in which $\mathbf{K}^{\mathrm{B}}$ is the beam element stiffness matrix, $\mathbf{f}^{\mathrm{B}}$ is a load vector, and $\mathbf{u}^{\mathrm{B}}$ is the displacement vector that contains $\mathbf{u}_{1}^{\mathrm{B}}$ and $\mathbf{u}_{2}^{\mathrm{B}}$ holding the standard nodal finite element degrees of freedom with regards to the two beam ends, respectively.

Thus, we achieve an accurate beam element governed by its degrees of freedom in all the nodes at the two end cross-sections. Furthermore, these degrees of freedom correspond to those in the joint element formulation sharing the same interface. Therefore, it is possible to assemble a beam element with a joint element having the same discretisation at the interfaces.
The beam cross-section analysis results in a set of beam solution modes containing orthogonal cross-sectional displacement fields, which we assemble as columns in the matrix $\mathbf{V}^{\mathrm{B}}$. In Figure 4 the cross-sectional displacement fields concerning the 'Advanced beam element 1' are shown on the left hand side of the beam end.

Using conventional finite element methods, it is possible to find a transformation between the three-dimensional beam modes and all the nodal degrees of freedom at the end cross-sections.

The degrees of freedom at each beam end cross-section $\left(\mathbf{u}_{1}^{\mathrm{B}}\right.$ and $\mathbf{u}_{2}^{\mathrm{B}}$ according to Equation (1) ) are transformed into orthogonal modal degrees of freedom with the following transformation:

$$
\mathbf{u}_{i}^{\mathrm{B}}=\mathbf{V}_{i}^{\mathrm{B}} \boldsymbol{\varphi}_{i}^{\mathrm{B}} \quad \text { for } i=1,2
$$




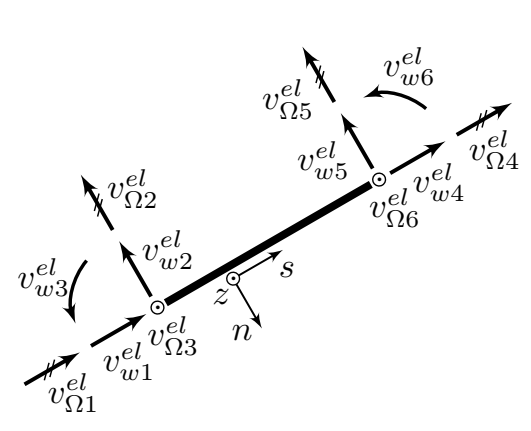

a)

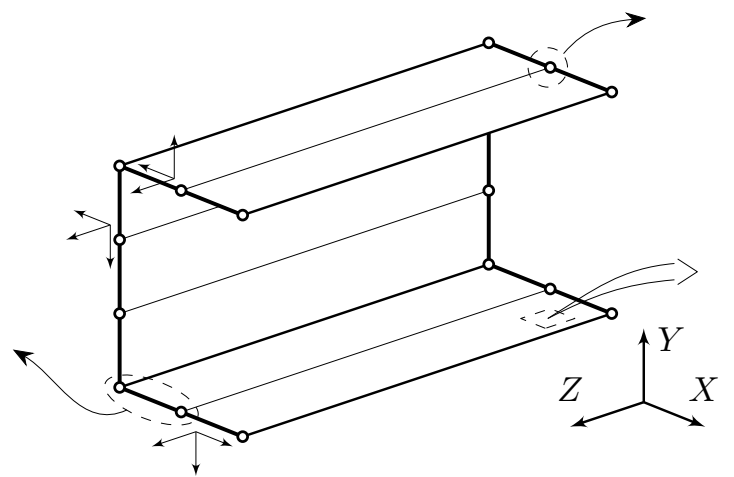

b)

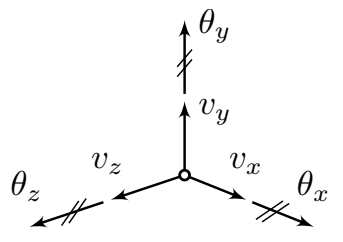

c)

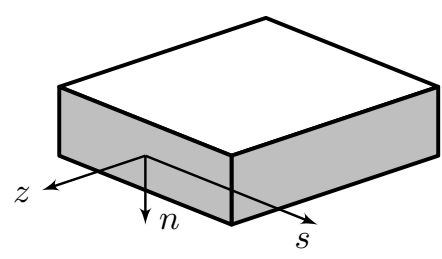

d)

Figure 5: Beam element: a) Wall element and its local degrees of freedom, b) Beam element with discretised end cross-sections, c) Nodal degrees of freedom, and d) Wall cut-out with the local coordinate system

where the column vector $\varphi_{i}^{\mathrm{B}}$ contains the modal degrees of freedom at the one end of the beam. In fact, these modal degrees of freedom correspond to intensities of the crosssectional displacement fields given as the columns in $\mathbf{V}^{\mathrm{B}}$. Then, the entire transformation of a beam element can be performed using the transformation matrix $\mathbf{T}^{\mathrm{B}}$ :

$$
\mathbf{u}^{\mathrm{B}}=\mathbf{T}^{\mathrm{B}} \boldsymbol{\varphi}^{\mathrm{B}} \quad \text { with } \mathbf{T}^{\mathrm{B}}=\left[\begin{array}{cc}
\mathbf{V}_{1}^{\mathrm{B}} & \cdot \\
\cdot & \mathbf{V}_{2}^{\mathrm{B}}
\end{array}\right], \quad \boldsymbol{\varphi}^{\mathrm{B}}=\left[\begin{array}{c}
\boldsymbol{\varphi}_{1}^{\mathrm{B}} \\
\boldsymbol{\varphi}_{2}^{\mathrm{B}}
\end{array}\right]
$$

where a single dot $[\cdot]$ represents a suitable zero-matrix. The matrices $\mathbf{V}_{1}^{\mathrm{B}}$ and $\mathbf{V}_{2}^{\mathrm{B}}$ contain the exact same modes and number of modes as we operate on a single beam element. The column vector $\varphi^{\mathrm{B}}$ contains the beam modal degrees of freedom, which is separated into $\varphi_{1}^{\mathrm{B}}$ and $\varphi_{2}^{\mathrm{B}}$ representing each of the beam end cross-sections, respectively.

Now, using the transformations in Equation (3) and applying the laws of transformation on the equation system in Equation (1) we have:

$$
\tilde{\mathbf{K}}^{\mathrm{B}} \varphi^{\mathrm{B}}=\tilde{\mathbf{f}}^{\mathrm{B}}
$$

where $\tilde{\mathbf{K}}^{\mathrm{B}}$ is the beam element modal stiffness matrix defines as:

$$
\tilde{\mathbf{K}}^{\mathrm{B}}=\mathbf{T}^{\mathrm{B}^{\mathrm{T}}} \mathbf{K}^{\mathrm{B}} \mathbf{T}^{\mathrm{B}}
$$

However, please note that, since solution modes formulate the beam element we may judiciously choose a relevant number of these modes in $\mathbf{V}^{\mathrm{B}}$ and perform a transformation of the end nodal degrees of freedom into a reduced number of modal degrees of freedom and hence, the equation system does not necessarily contain all modal degrees of freedom, but instead represents a reduced equation system.

\subsection{Joint elements}

The complexity met in connecting beam members and column members are accommodated by introducing a 'joint element'. This joint element is in itself an assembly of standard (shell) finite elements used to discretise the often complex plated joint geometry. The joint element is modelled so that the interfaces to the connected beams have the same nodes and nodal degrees of freedom. Hence, many 'joint element' geometries even including other types of special purpose finite elements can be incorporated in the joint model. Consequently, a single joint element allows a detailed assessment of displacements and stresses due to the finite element formulation, but the main drawback is the inclusion of a high number of degrees of freedom. The assembly of finite elements results in the following equation system:

$$
\mathbf{K}^{\lrcorner} \mathbf{u}^{\mathrm{J}}=\mathbf{f}^{\mathrm{J}} \quad \text { where } \mathbf{u}^{\mathrm{J}}=\left[\begin{array}{c}
\mathbf{u}_{1}^{\mathrm{J}} \\
\mathbf{u}_{2}^{\mathrm{J}} \\
\vdots
\end{array}\right]
$$

Here, $\mathbf{K}^{\mathrm{J}}$ is the stiffness matrix, $\mathbf{f}^{\mathrm{J}}$ is the load vector, and $\mathbf{u}^{\mathrm{J}}$ is the displacement vector, which is grouped into displacement vectors that contain the displacement degrees of freedom at each of the connected faces indicated by the index. If any secondary degrees of freedom exist within the joint element these may be condensed.

Since it is the idea to let the joint element interfaces be governed by the displacement fields of the connected beam elements then the nodal degrees of freedom at these connected faces are transformed into modal degrees of freedom governed by the related beam transformations from Equation (2). Hence, the nodal degrees of freedom at an interface are transformed into modal degrees of freedom using:

$$
\mathbf{u}_{i}^{\mathrm{J}}=\mathbf{V}_{j}^{\mathrm{B}} \varphi_{i}^{\mathrm{J}} \quad \text { for } i=1,2, . ., n_{\mathrm{I}}
$$

where index $i$ indicates an interface and $n_{\mathrm{I}}$ is the total number of connected faces for a single joint element. With respect to the example in Figure 4 this corresponds to $n_{\mathrm{I}}=3$. In Equation (7), $\mathbf{V}_{j}^{\mathrm{B}}$ is the exact same matrix 
used for the beam transformation in Equation (3) at the exact same interface and therefore index $j$ is a reference to which of the beam ends that is located at the interface, being either $j=1$ or $j=2$. Since the interfaces at a joint element not necessary contain the same number of nodes, the matrices $\mathbf{V}_{j}^{\mathrm{B}}$ may not be of the same size. Accordingly for the entire joint element in Figure 4 the transformation matrix will be:

$$
\mathbf{u}^{\mathrm{J}}=\mathbf{T}^{\mathrm{J}} \boldsymbol{\varphi}^{\mathrm{J}} \quad \text { with } \mathbf{T}^{\mathrm{J}}=\left[\begin{array}{ccc}
\mathbf{V}_{2}^{\mathrm{B} 1} & \cdot & \cdot \\
\cdot & \mathbf{V}_{1}^{\mathrm{B} 2} & \cdot \\
\cdot & \cdot & \mathbf{V}_{2}^{\mathrm{B} 3}
\end{array}\right]
$$

Then, applying the transformations from Equation (8) to the equation system in Equation $\sqrt{6}$ the mode-based equation system for the joint element will be:

$$
\tilde{\mathbf{K}}^{J} \varphi^{J}=\tilde{\mathbf{f}}^{\mathrm{J}} \quad \text { where } \varphi^{\mathrm{J}}=\left[\begin{array}{l}
\varphi_{1}^{\mathrm{J}} \\
\varphi_{2}^{\mathrm{J}} \\
\varphi_{3}^{\mathrm{J}}
\end{array}\right]
$$

where $\tilde{\mathbf{K}}^{J}$ is the joint element stiffness matrix transformed into modal space, $\varphi^{\mathrm{J}}$ is the modal displacement degrees of freedom, and $\tilde{\mathbf{f}}^{\mathrm{J}}$ is the load vector in modal space. Explicitly we define the joint element stiffness matrix and the modal displacement degree of freedom vector as:

$$
\tilde{\mathbf{K}}^{\jmath}=\mathbf{T}^{J^{\top}} \mathbf{K}^{J} \mathbf{T}^{J} \quad \text { and } \quad \tilde{\mathbf{f}}^{J}=\mathbf{T}^{J^{\top}} \mathbf{f}^{J}
$$

Note that the degrees of freedom at the interfaces are transformed into modal beam type displacements of the individually connected beam and thus, a judiciously chosen reduction in the number of degrees of freedom in the joint interfaces can be performed.

\subsection{Mode-based formulation}

Thus as mentioned, to increase efficiency, this methodology allows us to utilise the modal formulation of the beam elements to decreases the number of degrees of freedom. This is achieved by transforming the beam degrees of freedom in the interface section into a mode-based degree of freedom space, i.e. a mode space containing a few numbers of relevant and unique cross-section displacement fields. The joint elements are likewise transformed into a displacement-based mode formulation. Here, the nodal degrees of freedom at the interfaces are transformed into few beam modal degrees of freedom and the remaining internal degrees of freedom can be eliminated for example by condensation. This allows a mode-based assembly of the structural framework by assembly of the different element contributions from Equation (4) and (9). Hence, we end up with an equation system for the entire frame structure being in a modal format:

$$
\tilde{\mathbf{K}}^{\text {sys }} \varphi^{\text {sys }}=\tilde{\mathbf{f}}^{\text {sys }}
$$

This is achieved by using conventional assembly and transformation procedures as in the finite element method (see for example Cook et al. [76]).

\section{Illustration of key aspects}

The purpose of this section is to illustrate and highlight some of the key aspects of the idea. To do so, we examine a rectangular portal frame corner connecting two thin-walled lipped channel sections by a diagonally stiffened joint element. Furthermore, to ease the implementation, there are two minor joint elements incorporated at the beam and column ends, respectively. These are implemented as a continuation of the beam/column element to simplify the application of load and boundary conditions. The general configurations and dimensions concerning this example are illustrated in Figure 6. The modulus of elasticity used is given as: $E=210 \mathrm{GPa}$ and the Poisson ratio is: $\nu=0.3$. The boundary conditions are as follows: at point $\mathrm{A}$ and $\mathrm{C}$ the mid point of the web is restrained against any translation, and at point $\mathrm{B}$ the translation out of the frame-plane is restrained. Moreover, the crosssection in $\mathrm{A}$ is loaded by a vertical unit displacement $\delta$ applied at the upper flange on top of the lip. The portal frame corner is assessed by a first-order linear elastic analysis.

\subsection{The beam element}

The advanced beam theory used to model the beam and column members is an advanced theory, which includes cross-sectional deformations and allows for a mode-based formulation, resently developed by the authors [77, 78. This theory is based on the small displacement hypothesis as well as a linear elastic analysis of the beam crosssection. Using this theory, the cross-section is discretised by wall elements as illustrated in Figure 5 having six degrees of freedom at cross-section nodes. This new thinwalled beam theory embraces a shear variation through a

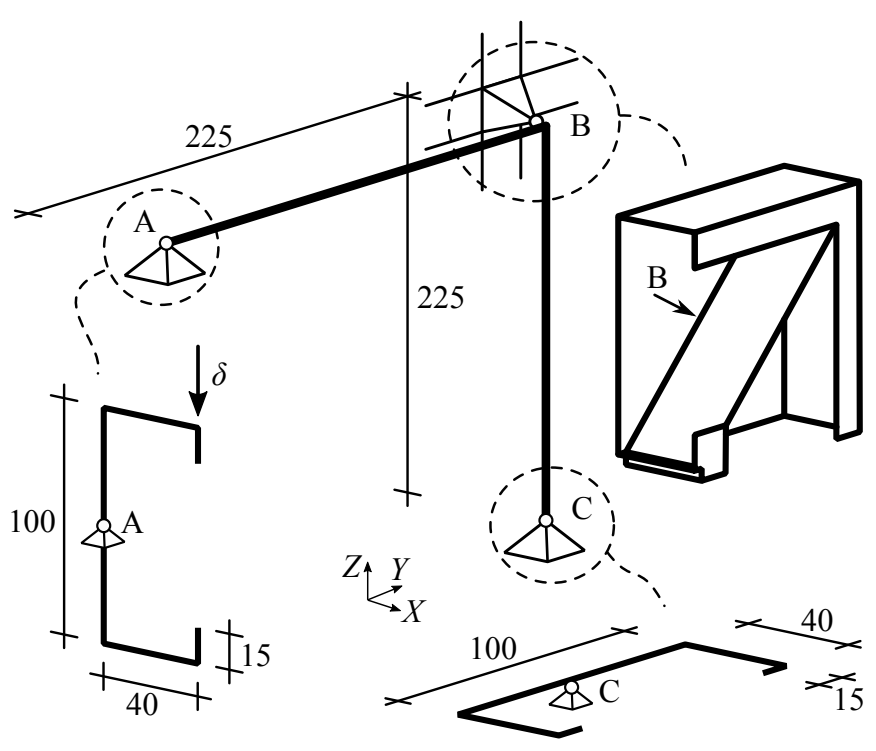

Figure 6: Frame set-up with load and support conditions. Dimensions in millimetre [mm] and the plate thickness is equal to $3 \mathrm{~mm}$ 


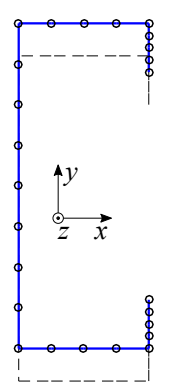

Mode 1

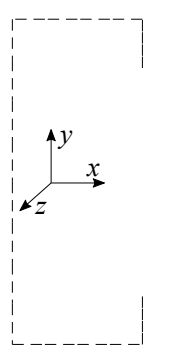

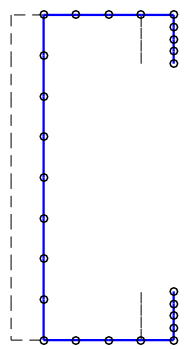

Mode 2

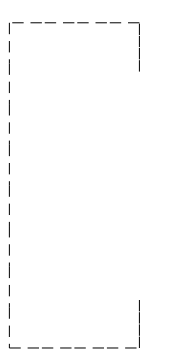

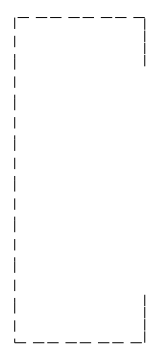

Mode 3

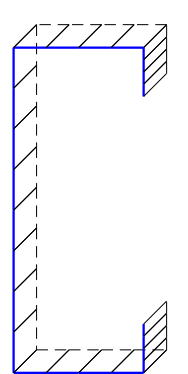

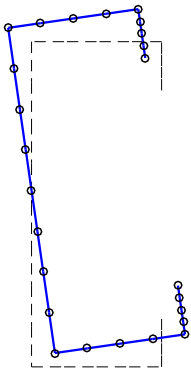

Mode 4

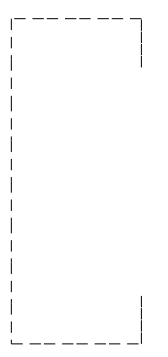

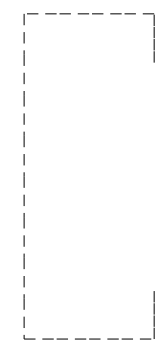

Mode 5

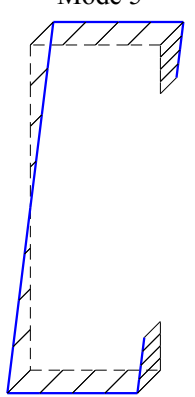

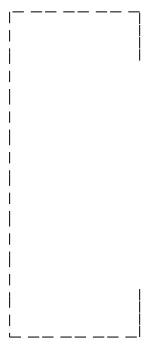

Mode 6

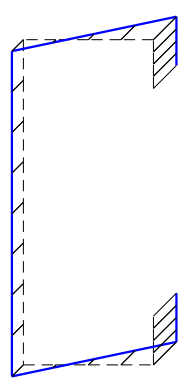

Figure 7: Interface modes 1-6 (the six rigid displacement fields). The upper row illustrates the translational part of the modes whereas the lower row represents the corresponding out-of-plane displacements (plotted in a local beam coordinate system)

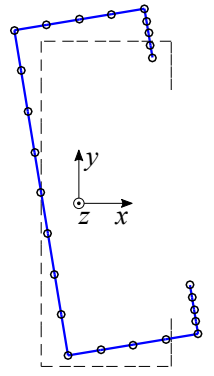

Mode 7

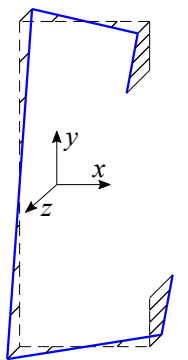

ratio: 23.2
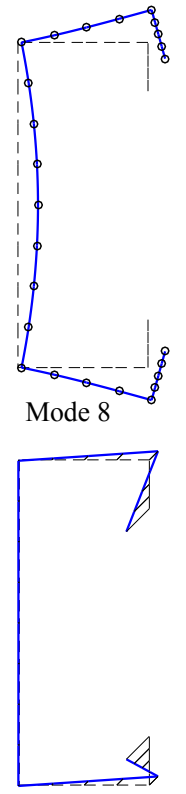

ratio: 10.7

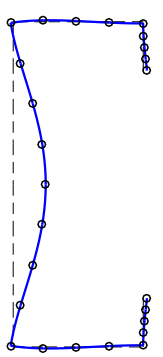

Mode 9

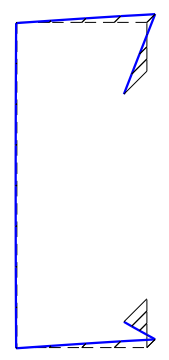

ratio: 0.47

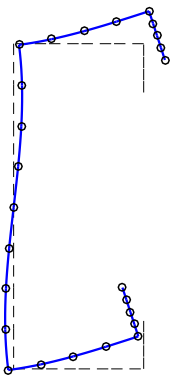

Mode 10

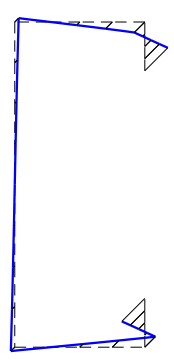

ratio: 9.20

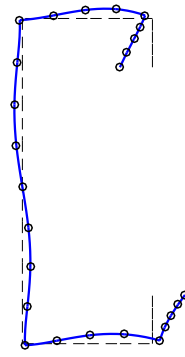

Mode 11

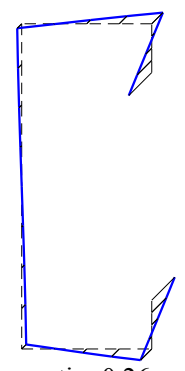

ratio: 0.26

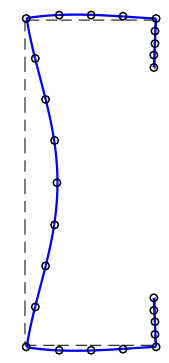

Mode 12

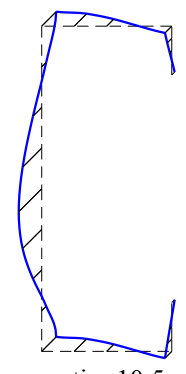

ratio: 10.5

Figure 8: Interface modes 7-12 (first six distortional modes). The upper row illustrates the translational part of the modes whereas the lower row represents the corresponding out-of-plane displacements (plotted in a local beam coordinate system). The 'ratio' indicates the scaling between the largest in-plane displacement and the largest out-ofplane displacement 


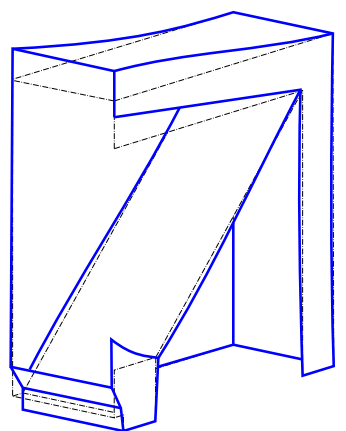

Mode 1

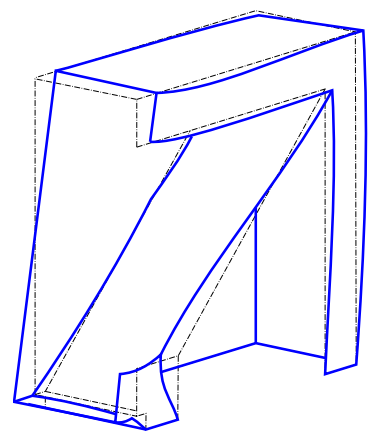

Mode 5

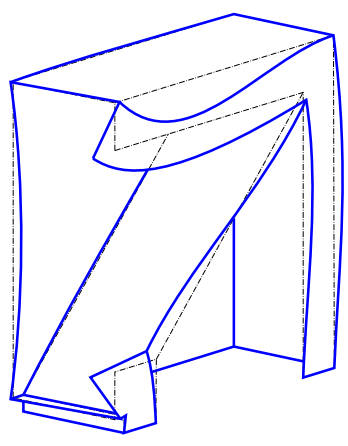

Mode 9

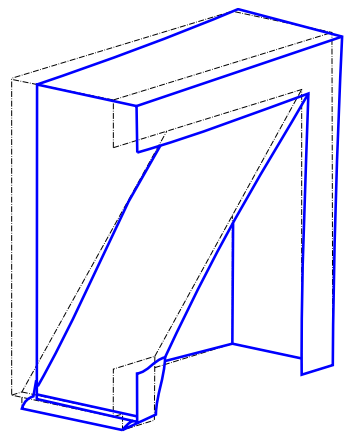

Mode 2

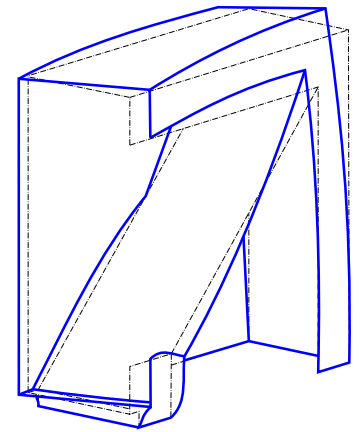

Mode 6

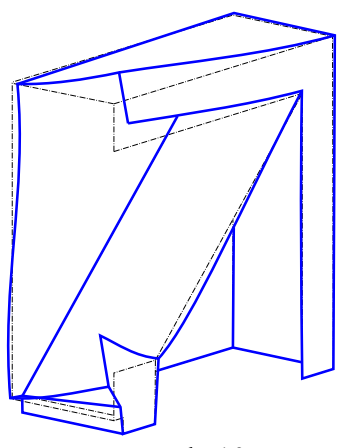

Mode 10

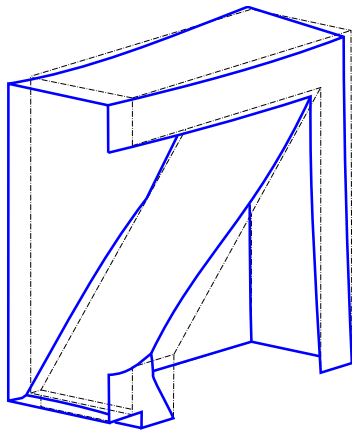

Mode 3

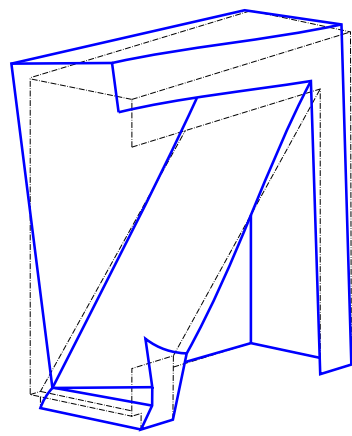

Mode 7

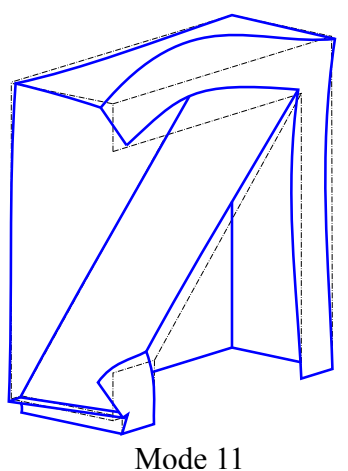

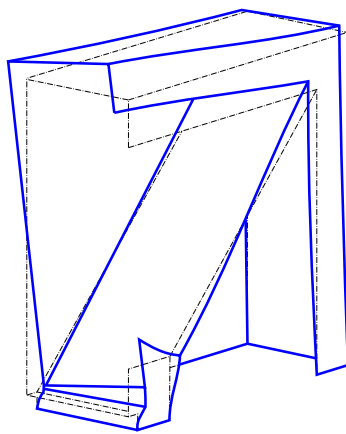

Mode 4
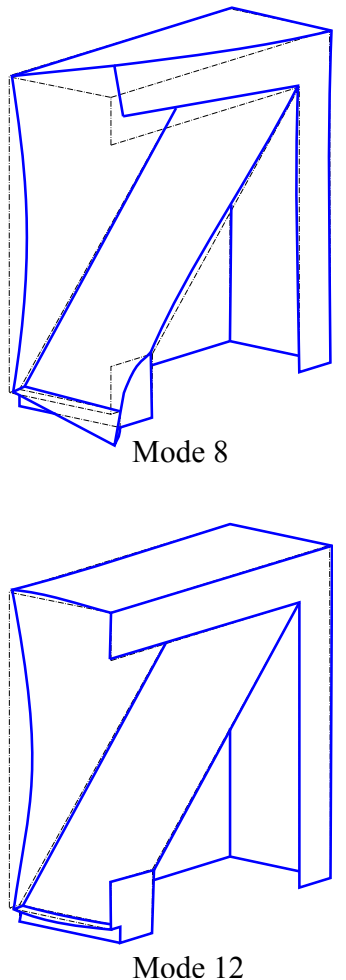

Figure 9: Joint deformation modes related to the first twelve modal degrees of freedom at the beam-to-joint interface

Timoshenko like beam behaviour and a Mindlin-Reissner like wall plate behaviour. Such a formulation is hardly found in other advanced beam theories despite the approach given by Miranda et al. [44, 79, who formulated a beam element in the framework of GBT, which probably also could have been used here.

The cross-section analysis results in a set of beam displacement modes that can be subdivided into crosssectional displacement fields and their associated axial amplitude functions, which describes the axial variation of the cross-sectional displacement field along the beam axis. These amplitude functions are either polynomials of maximum third-order (reflecting the twelve fundamental beam modes) or having exponential functions with varying decay (reflecting beam displacement modes of higher order). Each higher order mode has an exponential amplitude that decays away from one of the beam ends. This decay is con- trolled by a length scale parameter. The lower the length scale parameter, the longer the decay is. It is common practise to sort the modes based on their length scale since this often also reflect their influence.

In this example the cross-section is discretised into twenty-four wall elements; eight in the web panel and four in each of the other panels. This corresponds to 150 degrees of freedom, and in our case, this results in 150 unique interface modes (cross-sectional displacement fields) to be used for transforming both the beam and the column elements as well as the joint elements into the mode-based formulation. In fact, the transformation matrices $\mathbf{V}^{\mathrm{B}}$ in Equation (2) and (7) contains 150 columns representing the interface modes. These interface modes are deduced in the beam element cross-section analysis and are sorted with regards to decay length (this being related to the axial variation of the beam modes). To exemplify, the first 
twelve interface modes are illustrated in Figure 7 and 8 In fact, Figure 7 shows the six rigid cross-sectional interface modes and Figure 8 shows the next six modes, which are the first six distortional cross-sectional interface modes.

\subsection{The joint element}

The joint elements are discretised by use of triangular shell finite elements having six degrees of freedom at each node, see for example Cook et al. [76]. To be able to assemble beam and column members to a joint element, the joint element mesh is chosen in such a way that the nodes at the interfaces are in the exact same locations as the nodes of the adjacent beam and column cross-sections.

Based on the interface modes that are deduced during the beam element analysis and contained in $\mathbf{V}^{\mathrm{B}}$, each joint element is transformed into the mode-based formulation using the transformation in Equation (7). Hence, the displacement of a joint element may now be expressed in terms of modal degrees of freedom instead of conventional nodal degrees of freedom. To give a visual understanding of this modal degree of freedom formulation Figure 9 illustrates the effect of activating a single modal degree of freedom at a time. This has been done for the first twelve modal degrees of freedom at the beam-to-joint interface. Explicitly we have for Mode 1: $\varphi^{\mathrm{J}}=[1,0,0, \cdots]^{\top}$, for Mode 2: $\varphi^{\mathrm{J}}=[0,1,0,0, \cdots]^{\top}$ and so on for the remaining ten modes illustrated. In fact, the twelve modal degrees of freedom that are activated in Figure 9 corresponds to the twelve interface modes shown in Figure 7 and 8

\subsection{Assessment}

After the portal frame corner has been analysed by solving Equation (11) and according to the conditions given in Figure 6, we draw the deformed shape in Figure 10. To be observed is the ability to include the distortional deformations of the beam element due to the advanced beam element formulation. Furthermore, it is seen how the joint configuration is able to transmit both torsional and distortional deformation from the beam through the joint and into the column.

The frame corner has also been analysed using the commercial finite element program Abaqus [80. Here, triangular finite shell elements ( $\mathrm{S} 3$ in Abaqus nomenclature) with a maximum side length of $10 \mathrm{~mm}$ has been used to discretise the entire model. A brief comparison is given next.

The horizontal displacement at the upper left corner in cross-section A has been compared to the finite element model and a relative deviation of $-2.89 \%$ is found. At the same corner, Von Mises stresses are compared and shows a relative deviation of $-0.22 \%$. Furthermore, the entire Von Mises stress distribution of both models are shown in Figure 11. A close-up of the corner is shown in Figure 12. The colours represent the surface stress at the mid-point of each element(Note that the two colour scales are not identical within the scale from 0 to $80 \mathrm{MPa}$ ).

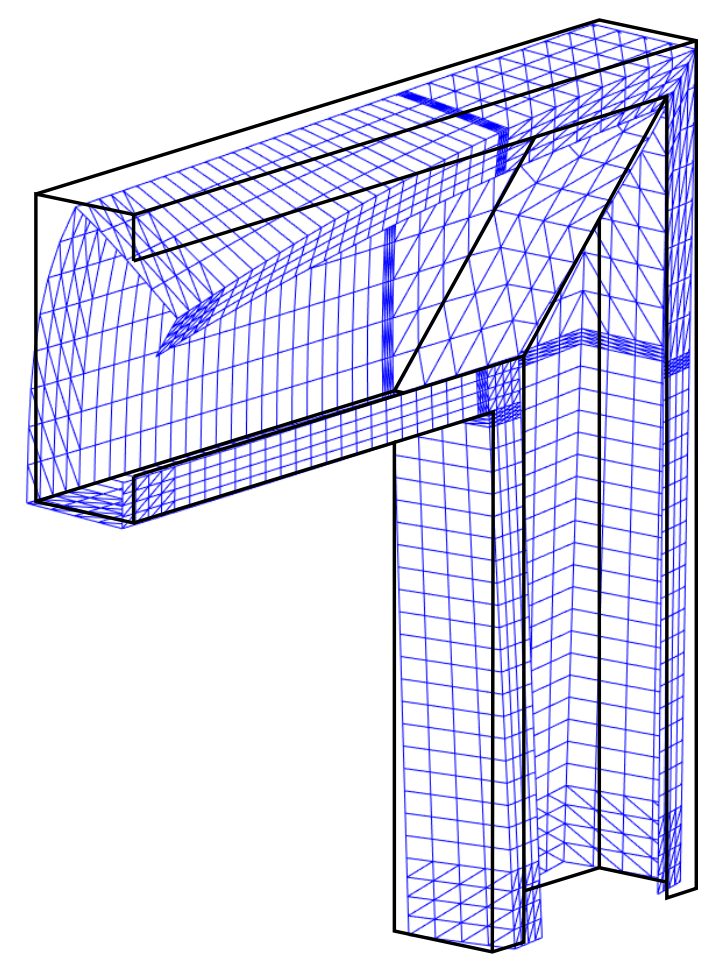

Figure 10: Full deformation pattern of the frame structure (the deformation is scaled 30 times)

\subsection{Displacement mode identification}

The main idea of this methodology is to identify those displacement modes that have an important influence on the structure and to reduce the number of included modes within the analysis. The joint element that connects the beam and the column is assessed in order to identify which modes that are activated at its interfaces. This assessment is shown in Figure 13. In Figure 13a the deformation of the joint element is drawn based on the present methodology. Furthermore, the deformations of the interfaces are shown as well. For comparison Figure 13 b shows the deformation of the corner from the Abaqus analysis. The intensities of the modal degrees of freedom at the two interfaces are determined directly as $\varphi^{\text {sys }}$ when solving the frame equation in Equation (11). These intensities are also illustrated in Figure 13 and 13 . Besides the deformation patterns, it should be observed that the activated interface modes are limited to the first number of modes. The primary modes are 1, 2, 4, 7, and 8; and 1, 2, 4, 7 and 8 for the beam-to-joint interface and the column-to-joint interface, respectively. Common to these modes is that they are either part of the polynomial modes or belong to the distortional modes that have a long decay length. This illustrates that a reduced set of modes related to the longer length scales of the modes of the connected beam elements may be chosen and that the influence of the modes having a short length scale may be neglected. This is one of the essential reasons for formulating this theory with a mode-based interface approach. This has been tested at the frame corner by performing an analysis including the 


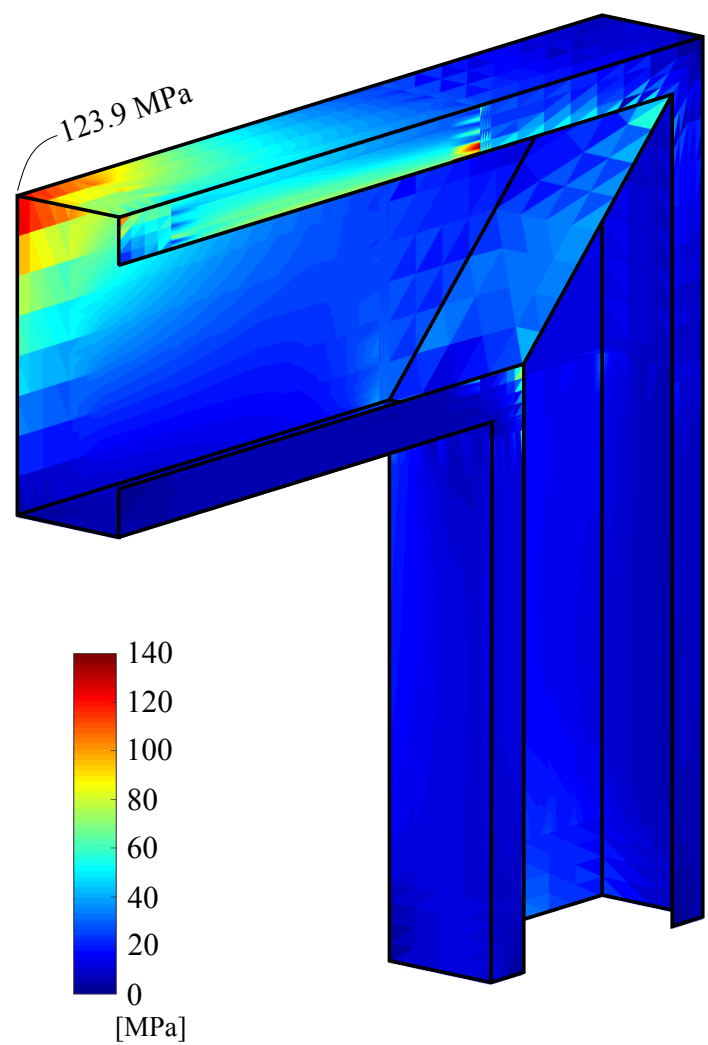

a)

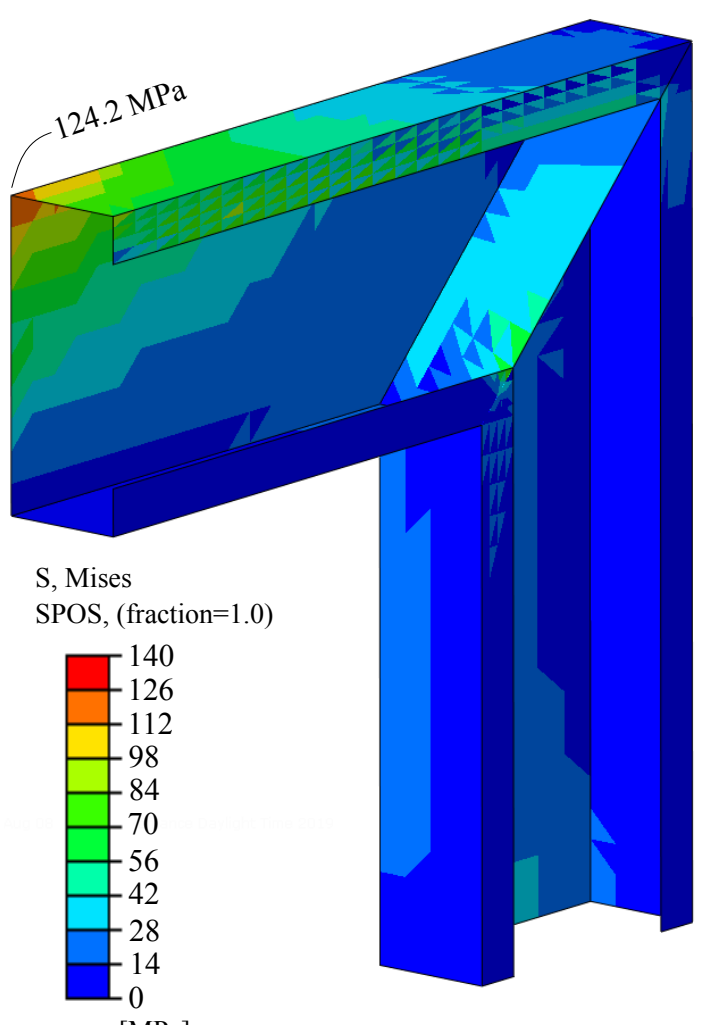

$[\mathrm{MPa}]$

b)

Figure 11: Three-dimensional illustration of the Von Mises surface stress in the frame. a) Present method; b) Abaqus model

first twenty modes at each interface only. If we then compare the displacements and Von Mises stresses at the upper left corner in cross-section A to the results obtained with the same methodology but with all 150 interface modes we get a relative deviation of $-2.1 \%$ for the displacements and $0.65 \%$ for the stresses.

\section{Discussion}

The motivation for this paper originates in several studies reporting that savings can be obtained by applying proper semi-rigid joint modelling. One of the popular methods is the mechanical one, namely the Component Method, which is adopted in the Eurocode 3 as well [1]. However, only global deformations are considered, and the method is limited to the transmission of bending moments. Other approaches exist, however, these are limited to the transmission of the seven generalised displacements of Vlasov beams. As a consequence, no cross-sectional distortion effects are taken into account at joints between non-aligned members despite the increasing amount of advanced beam theories, such as GBT and cFSM. These beam theories include this cross-sectional distortion effects, but the proper methodology to assemble these for global frame analysis with a reduced distortional and local mode space is lacking.

It is believed that the idea being presented in this paper enriches the analysis of connected non-aligned thin-walled beam members with a totally new mode-based interface approach that gives an in-depth insight into the mechanics of beam and joint behaviour. This new methodology may be used for optimising the joint design or may lead to better utilisation of materials within the entire frame structure. The methodology is mainly based on the use of beam-end displacement modes, formulated by standard nodal displacement parameters. The beam element used in this paper is based on an advanced beam theory developed by the authors [77, 78]. The formulation allows a displacement-based mode decomposition. Concerning the joint element, it is discretised by (shell) finite elements and therefore able to adopt complex geometries, for example including plate stiffeners. The technique presented has some similarity with that reported by Wu \& Mohareb [81] and Sahraei \& Mohareb [82, which models frame joints using shell elements and the structural members by conventional finite element beam elements. However, unlike the work in [81, 82], the present study captures distortional modes.

The beam and joint elements are transformed from a 


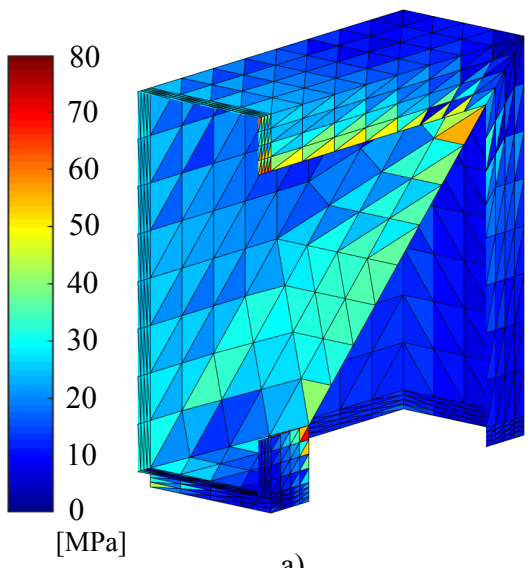

a)

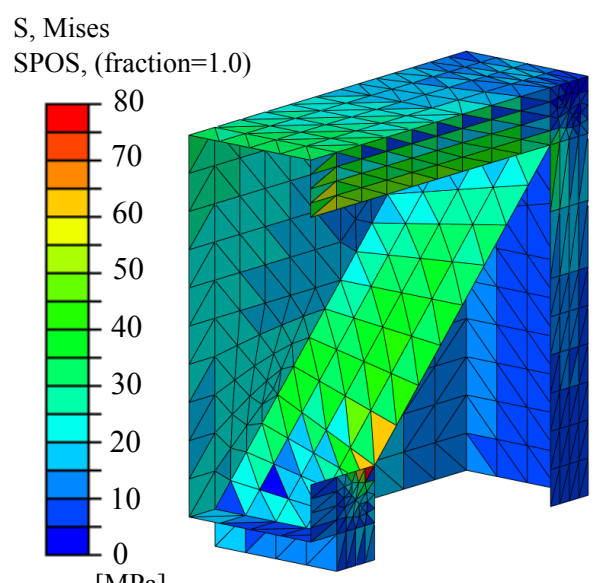

b)

Figure 12: Three-dimensional illustration of the Von Mises surface stress in the frame corner. a) present method; b) Abaqus model

standard degree of freedom space into a formulation governed by a few selected interface modes, which relates to the cross-section interface between beam elements and a joint. Hence, instead of having standard nodal degrees of freedom, a set of beam-end cross-sectional displacement fields are used as modal degrees of freedom. Such a mode could, for example, be a rigid translation of the crosssection or a distortional deformation (see Figure 7 and 8 .

Due to the use of an advanced beam theory as well as a detailed (shell) finite element discretisation of the joints, frame analysis can include very sophisticated deformation patterns. Comparing to the proposals based on Vlasov elements together with more overall joint formulations, such as the procedure presented by Shayan \& Rasmussen [34, shows that these approaches only include the warping effects and not the in-plane distortional effects.

Comparing this novel approach to full finite element analysis using shell elements, the amount of degrees of freedom required is orders of magnitude less, which results in much faster execution times for linear analysis with only a minor risk of decreasing accuracy. Moreover, the illustrative example indicates a reasonable agreement of the obtained displacements as well as Von Mises stresses when comparing the present approach to a commercial finite element model.

The presented methodology is more general than the approach given by Basaglia et al. within the framework of GBT 69, 70. Both methods are based on a mode-based displacement formulation using advanced beam elements that includes higher order effects. However, the GBT approach includes advanced beam elements, but the joint element formulation supports only the seven generalised displacements. Furthermore, in-depth prior knowledge of the joint mechanics is needed to establish constraint equations to ensure compatibility if including higher order displacement modes. In contrast, the joint element presented here includes the mechanical properties as well as being compatible at connected faces without prior assessment or constraint equations. In fact, due to the general formulation of the joint, it is believed that most displacementbased beam theories can adopt the presented methodology. The only requirement present is the need of a set of crosssectional displacement fields to be used for transforming the standard degrees of freedom at the cross-section interfaces into the chosen mode-based interface governed degree of freedom space. In this paper, the new methodology is illustrated by a single example that highlights some of the key aspects of this novel idea. The example clearly illustrates that only a limited number of interface modes are activated. Therefore, a reduction of degrees of freedom modes is a possibility (this, however, will vary depending on the corner and frame geometry).

Despite that this simple example does not include any connection components, such as bolts, it is known that such components can be implemented as springs or other elements as a part of the joint formulation. The stiffness of such components could perhaps also be adopted from the Component Method. Other possibilities and improvements that can be considered is the introduction of a bior multi-linear behaviour. In other words, the approach could be extended to have a set of rigid plastic displacement modes. This feature is essential because the regions near a connection are highly exposed to plastic behaviour. This type of response is often simplified in frame analysis using spring stiffness's [83, 84. Furthermore, research is needed to include both buckling and multi-linear elasticplastic analysis in this mode-based formulation.

\section{Acknowledgement}

The first author gratefully acknowledges the financial support given to a scholarship by the Danish consultancy company NIRAS A/S and the Innovation Fund Denmark (grant 5189-00005B). 


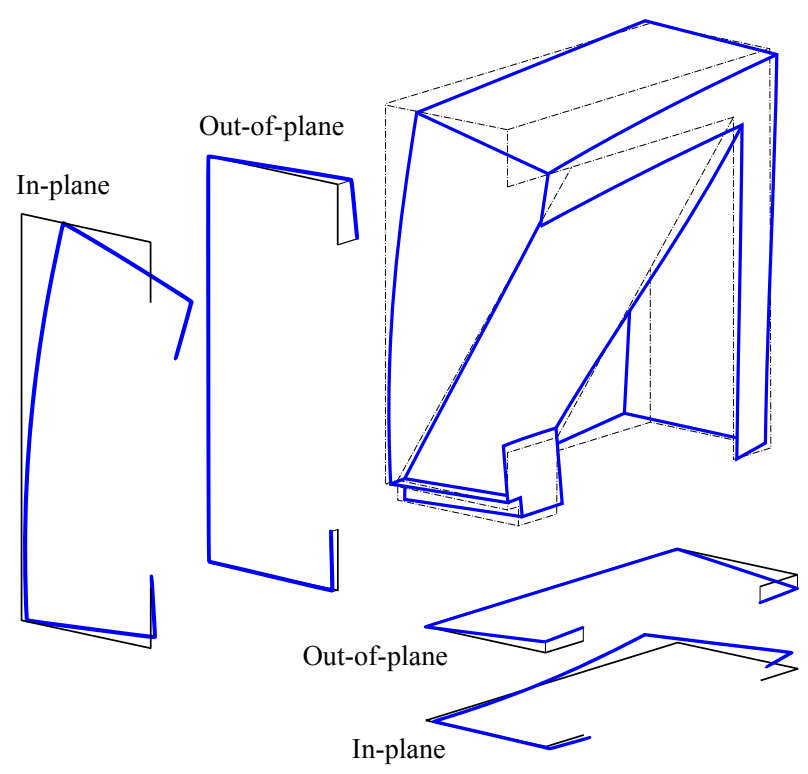

a)

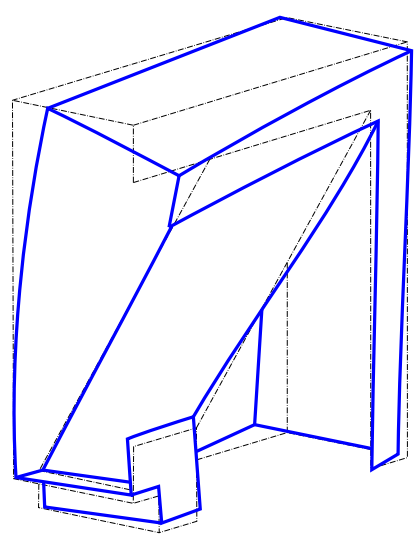

b)

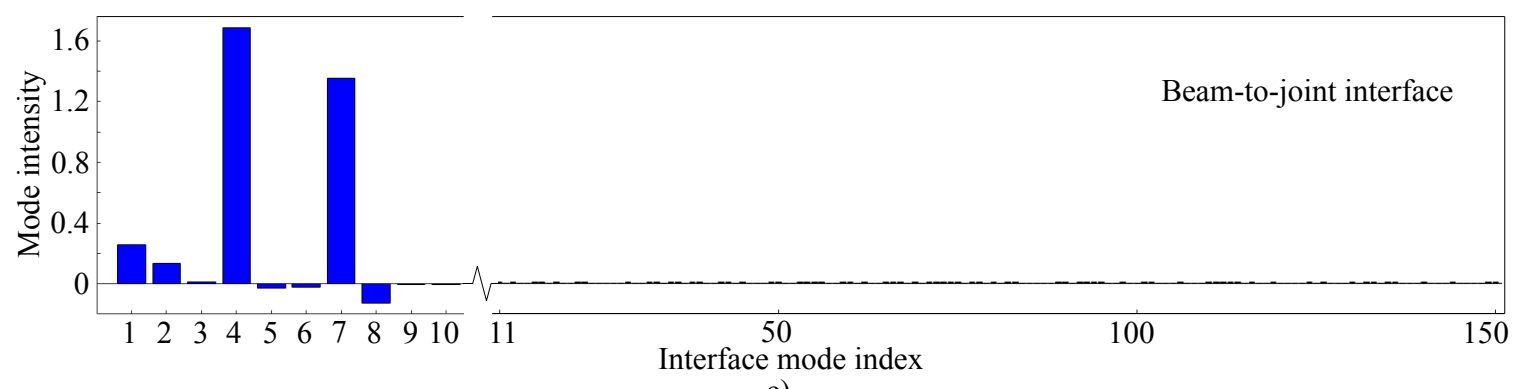

c)

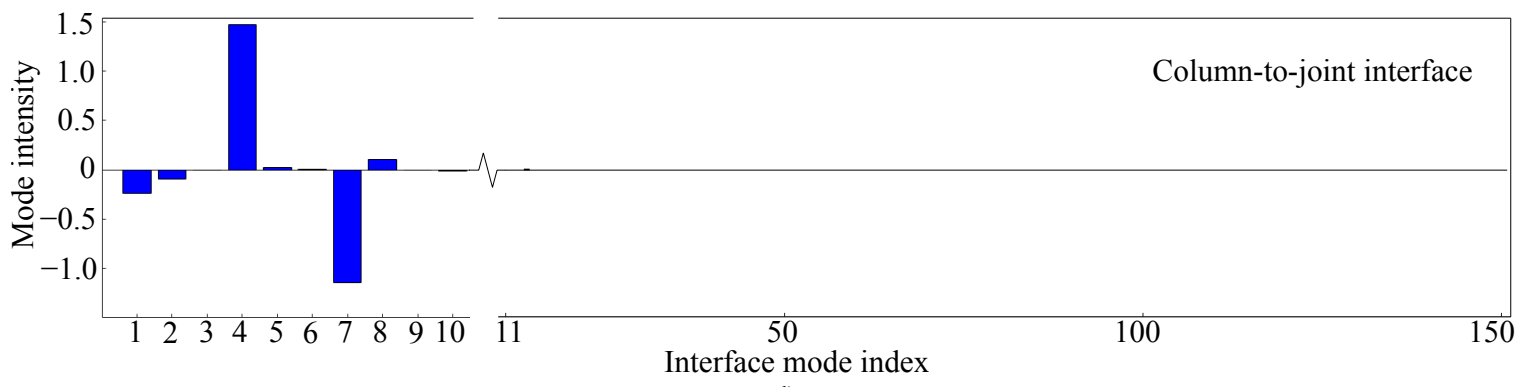

d)

Figure 13: Deformation of the joint element: a) based on the present method, b) from Abaqus shell model, c) intensities of the beam-to-joint interface modes, d) intensities of the column-to-joint interface modes 
[1] EN1993-1-8, Eurocode 3 - Design of steel structures. Part 1-8: Design of joints, 2nd Edition, CEN Brussels, 2007.

[2] S. W. Jones, P. A. Kirby, D. A. Nethercot, The analysis of frames with semi-rigid connections - a state-of-the-art report, Journal of Constructional Steel Research 3 (1983) 2-13. doi: 10.1016/0143-974X(83)90017-2

[3] K. C. Sarma, H. Adeli, Cost optimization of steel structures, Engineering Optimization 32 (2000) 777-802. doi:10.1080/ 03052150008941321

[4] C. Díaz, M. Victoria, O. M. Querin, P. Martí, Optimum design of semi-rigid connections using metamodels, Journal of Constructional Steel Research 78 (2012) 97-106. doi:10.1016/j. jcsr.2012.06.013

[5] R. Cunningham, Some aspects of semi-rigid connections in structural steelwork, Structural Engineer London (1990) 85-92.

[6] C. Bernuzzi, A. Pieri, V. Squadrito, Warping influence on the static design of unbraced steel storage pallet racks, Thin-Walled Structures 79 (2014) 71-82. doi:10.1016/j.tws.2014.01.024

[7] M. Abambres, D. Camotim, N. Silvestre, K. J. R. Rasmussen, GBT-based structural analysis of elastic-plastic thin-walled members, Computers and Structures 136 (2014) 1-23. doi: 10.1016/j.compstruc.2014.01.001

[8] W. M. Wilson, H. F. Moore, Tests to determine the rigidity of riveted joints of steel structures, Bulletin of the University of Illinois Engineering Experiment Station 104 (1917) 55pp.

[9] Steel Structures Research Committee, Final report of the steel structures research committee, Nature 139 (1937) 5-6. doi: 10.1038/139005a0

[10] P. Zoetemeijer, Summary of the research on bolted beam-tocolumn connections, Tech. rep., TU-Delft, report 25-6-90-2 (1990).

[11] C. Díaz, P. Martí, M. Victoria, O. M. Querin, Review on the modelling of joint behaviour in steel frames, Journal of Constructional Steel Research 67 (2011) 741-758. doi:10.1016/j. jcsr.2010.12.014

[12] K. Weynand, J. P. Jaspart, M. Steenhuis, The stiffness model of revised Annex J of Eurocode 3, in: R Bjorhovde and A Colson and $\mathrm{R}$ Zandonini (Eds.), Connections in Steel Structures III. Procedings of the 3rd Int. Workshop on Connections, Elsevier, Trento (1996) 441-452.

[13] J.-P. Jaspart, K. Weynand, Design of Joints in Steel and Composite Structures, ECCS - European Convention for Constructional Steelwork, 2016.

[14] E. Bayo, J. M. Cabrero, B. Gil, An effective component-based method to model semi-rigid connections for the global analysis of steel and composite structures, Engineering Structures 28 (2006) 97-108. doi:10.1016/j.engstruct.2005.08.001.

[15] E. Bayo, A. Loureiro, M. Lopez, L. S. da Silva, General component based cruciform finite elements to model $2 \mathrm{~d}$ steel joints with beams of equal and different depths, Engineering Structures 152 (2017) 698-708. doi:10.1016/j.engstruct.2017.09. 042

[16] L. S. da Silva, A. G. Coelho, E. L. Neto, Equivalent postbuckling models for the flexural behaviour of steel connections, Computers and Structures 77 (2000) 615-624. doi: 10.1016/S0045-7949(00)00015-8

[17] C. Zhu, K. J. R. Rasmussen, S. Yan, Generalised component model for structural steel joints, Journal of Constructional Steel Research 153 (2019) 330-342. doi:10.1016/j.jcsr.2018.10. 026

[18] S. P. Timoshenko, Theory of bending, torsion and buckling of thin-walled members of open cross section, Journal of the Franklin Institute 239 (1945) 201-219, part I. doi:10.1016/ 0016-0032(45)90093-7.

[19] S. P. Timoshenko, Theory of bending, torsion and buckling of thin-walled members of open cross section, Journal of the Franklin Institute 239 (1945) 249-268, part II. doi:10.1016/ 0016-0032(45)90161-X.

[20] S. P. Timoshenko, Theory of bending, torsion and buckling of thin-walled members of open cross section, Journal of the Franklin Institute 239 (1945) 343-361, part III. doi:10.1016/
0016-0032(45)90013-5

[21] W. Flügge, K. Marguerre, Wölbkräfte in dünnwandingen profilstäben, Ingenieur-archiv 18 (1) (1950) 23-38, published by Springer-Verlag, (in German). doi:10.1007/BF00537588

[22] V. Z. Vlasov, Thin-Walled Elastic Beams, 2nd Edition, Jerusalem, 1961, Israel program for scientific translations.

[23] C. F. Kollbrunner, N. Hajdin, Dünnwandige Stäbe · Band 1, Stäbe mit undeformierbaren Querschnitten, Springer-Verlag, 1972

[24] D. Krajcinovic, A consistent discrete elements technique for thinwalled assemblages, International Journal of Solids and Structures 5 (1969) 639-662. doi:10.1016/0020-7683(69) 90085-7.

[25] R. S. Barsoum, R. H. Gallagher, Finite element analysis of torsional and torsional-flexural stability problems, International Journal for Numerical Methods in Engineering 2 (1970) 335352. doi:10.1002/nme.1620020304

[26] A. H. Baigent, G. J. Hancock, Structural analysis of assemblages of thin-walled members, Engineering Structures 4 (1982) 207216. doi:10.1016/0141-0296(82)90010-4

[27] P. Vacharajittiphan, N. S. Trahair, Warping and distortion at Isection joints, Journal of the Structural Division (ASCE) (1974) $547-564$.

[28] P. J. B. Morrel, J. R. Riddington, F. A. Ali, H. A. Hamid, Influence of joint detail on the flexural torsional interaction of thin-walled structures, Thin-Walled Structures 24 (1996) 97111. doi:10.1016/0263-8231(95)00048-8

[29] P. W. Sharman, Analysis of structures with thin-walled open sections, International Journal of Mechanical Sciences 27 (1985) 665-677. doi:10.1016/0020-7403(85)90048-7

[30] S. Krenk, L. Damkilde, Warping of joints in i-beam assemblages, Journal of Engineering Mechanics (ASCE) 117 (1991) 24572474.

[31] A. Masarira, The effect of joints on the stability behaviour of steel frame beams, Journal of Constructonal Steel Research 58 (2002) 1375-1390. doi:10.1016/S0143-974X(02)00017-2.

[32] Y.-B. Yang, W. McGuire, A procedure for analysing space frames with partial warping restraint, International Journal for Numerical Methods in Engineering 20 (1984) 1377-1398. doi:10.1002/nme.1620200803

[33] G. S. Tong, X. X. Yan, L. Zhang, Warping and bimoment transmission through diagonally stiffened beam-to-column joints, Journal of Constructional Steel Research 61 (2005) 749-763. doi:10.1016/j.jcsr.2004.12.002

[34] S. Shayan, K. J. R. Rasmussen, A model for warping transmission through joints of steel frames, Thin-Walled Structures 82 (2014) 1-12. doi:10.1016/j.jtws.2014.03.017.

[35] R. Schardt, Eine erweiterung der technishen biegelehre für die berechnung biegestreifer prismatischer falfwerke, Der Stahlbau 35 (1966) 161-171.

[36] R. Schardt, Verallgemeinerte Technische Biegetheorie - Band 1, Lineare Theorie, 2nd Edition, Metrum-Verlag,Darmstadt, 1989.

[37] C. F. Kollbrunner, N. Hajdin, Dünnwandige Stäbe · Band 2, Stäbe mit deformierbaren Querschnitten, Nicht-elastisches Verhalten dünnwandiger Stäbe, Springer-Verlag, 1975.

[38] J. M. Davies, P. Leach, First-order generalised beam theory, Journal of Constructional Steel Research 31 (1994) 187-220. doi:10.1016/0143-974X(94)90010-8

[39] J. M. Davies, P. Leach, D. Heinz, Second-order generalised beam theory, Journal of Constructional Steel Research 31 (1994) 221-241. doi : 10.1016/0143-974X(94)90011-6

[40] N. Silvestre, D. Camotim, First-order generalised beam theory for arbitrary orthotropic materials, Thin-Walled Structures 40 (2002) 755-789. doi:10.1016/S0263-8231(02)00025-3

[41] N. Silvestre, D. Camotim, Second-order generalised beam theory for arbitrary orthotropic materials, Thin-Walled Structures 40 (2002) 791-820. doi:10.1016/S0263-8231(02)00026-5

[42] N. Silvestre, D. Camotim, Nonlinear generalized beam theory for cold-formed steel members, International Journal of Structural Stability and Dynamics 3 (4) (2003) 461-490. doi: 10.1142/S0219455403001002. 
43] R. Gonçalves, M. Ritto-Corrêa, D. Camotim, A new approach to the calculation of cross-section deformation modes in the framework of generalized beam theory, Computational Mechanics 46 (2010) 759-781. doi:10.1007/s00466-010-0512-2

[44] S. de Miranda, A. Gutiérrez, R. Miletta, F. Ubertini, A generalized beam theory with shear deformation, Thin-Walled Structures 67 (2013) 88-100. doi:10.1016/j.tws.2013.02.012

[45] D. Camotim, C. Basaglia, N. Silvestre, GBT Buckling Analysis of Thin-Walled Steel Frames: A State-of-the-art Report, Thin-Walled Structures 48 (2010) 726-743. doi:10.1016/j. tws.2009.12.003

46] D. Camotim, C. Basaglia, Buckling Analysis of Thin-Walled Structures Using Generalized Beam Theory (GBT): A Stateof-the-art Report, Steel Construction 6 (2013) 117-131. doi: $10.1002 /$ stco.201310021

[47] W. H. Wittrick, General sinusoidal stiffness matrices for buckling and vibration analyses of thin flat-walled structures, International Journal of Mechanical Sciences 10 (1968) 949-966. doi: 10.1016/0020-7403(68)90049-0

[48] J. S. Przemieniecki, Finite element structural analysis of local instability, AIAA Journal (American Institute of Aeronautics and Astronautics Journal) 11 (1) (1973) 33-39. doi:10.2514/ 3.50433

[49] Y. K. Cheung, Finite Strip Method in Structural Analysis, Pergamon Press, Oxford, New York, Toronto, Sydney, Paris, Frankfurt, 1976.

[50] G. J. Hancock, Distortional buckling of steel storage rack columns, Journal of Structural Engineering 111 (1985) 27702783. doi:10.1061/(ASCE) 0733-9445(1985) 111:12(2770)

[51] S. Ádány, B. W. Schafer, Buckling mode decomposition of single-branched open-section members via finite strip method: Derivation, Thin-Walled Structures 44 (2006) 563-584. doi: 10.1016/j.tws.2006.03.013

[52] S. Adány, B. W. Schafer, Buckling mode decomposition of single-branched open-section members via finite strip method: Application and examples, Thin-Walled Structures 44 (2006) 585-600. doi:10.1016/j.tws.2006.03.014

[53] S. Ádány, B. W. Schafer, A full modal decomposition of thinwalled, single-branched open cross-section members via the constrained finite strip method, Journal of Constructional Steel Research 64 (1) (2008) 12-29. doi:10.1016/j.jcsr.2007.04.004

[54] Z. Li, J. C. B. Abreu, J. Leng, S. Ádány, B. W. Schafer, Review: Constrained finite strip method developments and applications in cold-formed steel design, Thin-Walled Structures 81 (2014) 2-18. doi:10.1016/j.tws.2013.09.004

[55] N. Silvestre, D. Camotim, N. F. Silva, Generalized beam theory revisited: from kinematical assumptions to the deformation mode determination, International Journal of Structural Stability and Dynamics 11 (2011) 969-997. doi:10.1142/ S0219455411004427

[56] S. Ádány, N. Silvestre, B. W. Schafer, D. Camotim, GBT and cFSM: Two modal approaches to the buckling analysis of unbranched thin-walled members, Advanced Steel Construction 5 (2) (2009) 195-223.

[57] J. Jönsson, Distortional theory of thin-walled beams, ThinWalled Structures 33 (1999) 269-303. doi:10.1016/ S0263-8231(98) 00050-0

[58] J. Jönsson, M. J. Andreassen, Distortional eigenmodes and homogeneous solutions for semi-discretized thin-walled beams, Thin-Walled Structures 49 (2011) 691-707. doi:10.1016/j. tws. 2010.12.009

[59] M. J. Andreassen, J. Jönsson, Distortional solutions for loaded semi-discretized thin-walled beams, Thin-Walled Structures 50 (2012) 116-127. doi:10.1016/j.tws.2011.08.013

[60] M. J. Andreassen, J. Jönsson, Distortional buckling modes of semi-discretized thin-walled columns, Thin-Walled Structures 51 (2012) 53-63. doi:10.1016/j.tws.2011.11.002

[61] R. F. Vieira, F. B. E. Virtuoso, E. B. R. Pereira, A higher order thin-walled model including warping and shear modes, International Journal of Mechanical Sciences (2013) 67-82 doi: 10.1016/j.ijmecsci.2012.10.009
[62] R. F. Vieira, F. B. Virtuoso, E. B. R. Pereira, A higher order model for thin-walled structures with deformable crosssections, International Journal of Solids and Structures (2014) 575-598doi:10.1016/j.ijsolstr.2013.10.023

[63] G. Garcea, R. Gonçalves, A. Billota, D. Manta, R. Bebiano, N. Leonetti, D. Magisano, D. Camotim, Deformation modes of thin-walled members: a comparison between the method of generalized eigenvectors and generalized beam theory, Thin-Walled Structures 100 (2016) 192-212. doi:10.1016/j.tws.2015.11. 013

[64] S. Ádány, Shell element for constrained finite element analysis of thin-walled structural members, Thin-Walled Structures 105 (2016) 135-146. doi:10.1016/j.tws.2016.04.012

[65] S. Ádány, Constrained shell finite element method for thinwalled members with holes, Thin-Walled Structures 121 (2017) 41-56. doi:10.1016/j.tws.2017.09.021

[66] S. Adány, Constrained shell finite element method for thinwalled members, part 1: constraints for single band or finite elements, Thin-Walled Structures 128 (2018) 43-55. doi: $10.1016 / j . t w s .2017 .01 .015$

[67] S. Adány, D. Visy, R. Nagy, Constrained shell finite element method, part 2: application to linear buckling analysis of thinwalled members, Thin-Walled Structures 128 (2018) 56-70. doi: 10.1016/j.tws.2017.01.022

[68] D. Camotim, N. Silvestre, C. Basaglia, R. Bebiano, GBT-based buckling analysis of thin-walled members with non-standard support conditions, Thin-Walled Structures 46 (2008) 800-815. doi:10.1016/j.tws.2008.01.019

[69] C. Basaglia, D. Camotim, N. Silvestre, Global Buckling Analysis of Plane and Space Thin-Walled Frames in the Context of GBT, Thin-Walled Structures 46 (2008) 79-101. doi:10.1016/ j.tws.2007.07.007

[70] C. Basaglia, D. Camotim, N. Silvestre, GBT-based local, distortional and global buckling analysis of thin-walled steel frames, Thin-Walled Structures 47 (2009) 1246-1264. doi:10.1016/j. tws.2009.04.003

[71] C. Basaglia, D. Camotim, N. Silvestre, GBT-based buckling analysis of thin-walled steel frames with arbitrary loading and support conditions, International Journal of Structural Stability and Dynamics 10 (2010) 363-385. doi:10.1142/ S0219455410003531

[72] C. Basaglia, D. Camotim, N. Silvestra, Torsion warping transmission at thin-walled frame joints: Kinematics, modelling and structural response, Journal of Constructional Steel Research 69 (2012) 39-53. doi:10.1016/j.jcsr.2011.07.016

[73] C. Basaglia, D. Camotim, N. Silvestre, Post-buckling analysis of thin-walled steel frames using generalised beam theory (gbt), Thin-Walled Structures 62 (2013) 229-242. doi: 10.1016/j.tws.2012.07.003

[74] C. Basaglia, D. Camotim, N. Silvestre, Buckling and vibration analysis of cold-formed steel chs members and frames using generalized beam theory, International Journal of Structural Stability and Dynamics 15 (2015) 1540021. doi:10.1142/ S0219455415400210

[75] C. Basaglia, D. Camotim, H. B. Coda, Generalized beam theory (GBT) formulation to analyse the vibration behaviour of thinwalled steel frames, Thin-Walled Structures 127 (2018) 259-274. doi:10.1016/j.tws.2018.01.038

[76] R. D. Cook, D. S. Malkus, M. E. Plesha, Concepts and applications of finite element analysis, 3rd Edition, John Wiley \& Son, NewYork Chichester Brisbane Toronto Singapore, 1989.

[77] A. B. Hansen, J. Jönsson, Displacement modes of a thin-walled beam model with deformable cross sections, Thin-Walled Structures 141 (2019) 576-592. doi:10.1016/j.tws.2019.01.052

78] A. B. Hansen, J. Jönsson, A thin-walled beam element formulated on exact displacement modes, approved for publishing in: Thin-Walled Structures (2019).

[79] S. de Miranda, A. Madeo, R. Miletta, F. Ubertini, On the relationship of the shear deformable generalized beam theory with classical and non-classical theories, International Journal of Solids and Structures 51 (2014) 3698-3709. doi:10.1016/j. 
ijsolstr.2014.07.001

[80] Abaqus, Abaqus/CAE 2016; Abaqus $^{\circledR}$ and SIMULIA ${ }^{\circledR}$ used for finite element analysis, 2016, abaqus Inc., SIMULIA $\odot$ Dassault Systèmes, 2015, Version 2016.

[81] L. Wu, M. Mohareb, Finite-element formulation for the lateral torsional buckling of plane frames, Journal of Engineering Mechanics 139 (2013) 512-524. doi:10.1061/(ASCE)EM. 1943-7889.0000492.

[82] A. Sahraei, M. Mohareb, Lateral torsional buckling analysis of moment resisting plane frames, Thin-Walled Strucures 134 (2019) 233-254. doi:10.1016/j.tws.2018.10.006

[83] S.-E. Kim, S.-H. Choi, Practical advanced analysis for semi-rigid space frames, International Journal of Solids and Structures 38 (2001) 9111-9131. doi:10.1016/S0020-7683(01)00141-X

[84] R. G. L. da Silva, A. C. C. Lavall, R. S. Costa, H. F. Viana, Formulation for second-order inelastic analysis of steel frames including shear deformation effect, Journal of Constructional Steel Research 151 (2018) 216-227. doi:10.1016/j.jcsr.2018. 09.011 